\title{
Tool wear and spring back analysis in orthogonal machining unidirectional CFRP with respect to tool geometry and fibre orientation
}

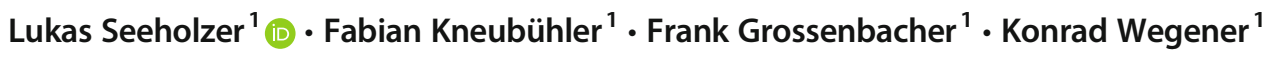 \\ Received: 18 January 2021 / Accepted: 3 May 2021 / Published online: 31 May 2021 \\ (C) The Author(s) 2021
}

\begin{abstract}
Machining abrasive carbon fibre reinforced polymers (CFRP) is characterised by extensive mechanical wear. In consequence, the cutting edge micro-geometry and thus the tool/material contact situation are continuously changing, which affects process forces and machining quality. As a conclusion, a fundamental understanding of the tool wear behaviour and its influencing factors is crucial in order to improve performance and lifetime of cutting tools. This paper focuses on a fundamental tool wear analysis of uncoated tungsten carbide cutting inserts with different combinations of fibre cutting angles and tool geometries. For this purpose, orthogonal machining experiments with unidirectional CFRP material are conducted, where the wear progression of the micro-geometry is investigated by means of five wear parameters $l_{\alpha}, l_{\gamma}, \gamma^{*}, \alpha^{*}$, and $b_{c}$. For detecting the actual contact zone of the cutting edge and to measure the elastic spring back of the material, the flank face is marked via short pulsed laser processing. Furthermore, the process forces and the wear rate are measured. It is shown that the material loss due to wear clearly varies along the tool's contact region and is highly dependent on the clearance angle and the fibre cutting angle $\Phi$, while the influence of the tested rake angles is mostly negligible. Especially in machining $\Phi=30^{\circ}$ and $\Phi=60^{\circ}$, a strong elastic spring back is identified, which is more intense for smaller clearance angles. For all tested configurations, the material's elastic spring back increases in intensity as wear progresses which, in combination with the decreasing clearance angle, is the main reason for high thrust forces.
\end{abstract}

Keywords Fibre reinforced plastic $\cdot$ Composite $\cdot$ Cutting $\cdot$ Cutting edge $\cdot$ Spring back $\cdot$ Tool $\cdot$ Wear

\section{Introduction}

Carbon fibre reinforced polymers (CFRP) are characterised by outstanding specific strength and stiffness properties that make them particularly suitable for light weight constructions in aerospace industries $[1,2]$. Although CFRP components are usually designed and manufactured near-net-shape, conventional machining operations are often required to fulfil quality standards as stated by Wan et al. [3]. According to Khanna et al. [4], turning, milling, and drilling are the most important machining operations associated with manufacturing applications in CFRP. In this context, Geier et al. [2]

Lukas Seeholzer

seeholzer@iwf.mavt.ethz.ch

1 Institute of Machine Tools and Manufacturing (IWF), ETH Zürich, Leonhardstrasse 21, 8092 Zurich, Switzerland grouped the main machining activities into three groups: machining difficult-to-mold features like pockets and holes (i), increasing the surface quality by edge trimming (ii), and fulfilling other dimensional requirements (iii).

As stated by Sheikh-Ahmad [5], machining CFRP is challenging due to the material's heterogeneity and the anisotropic material properties resulting in fibre cutting angle dependent chip formation mechanisms as documented by numerous experimental studies [6-9]. Furthermore, the abrasive carbon fibres cause excessive tool wear during machining as exemplarily shown by Maegawa et al. [10] by means of downmilling unidirectional (UD) CFRP material. Wang et al. [11] identified mechanical wear as the main cause for tool wear in machining CFRP, whereas thermal and chemical wear effects play minor roles due to the comparable low process temperatures and the chemical inertness of the material.

The occurring tool wear is associated with the tool/ workpiece interactions in the contact zone of the cutting tool that in accordance with Sheikh-Ahmad [5] varies significantly 
for different fibre orientations. Therefore, numerous researchers [8, 12-14] have focussed on analysing the tool wear characteristics depending on the fibre orientation. According to Dandekar et al. [15], these fundamental investigations are usually done by using orthogonal machining operations with UD CFRP material due to the reduced complexity of the machining kinematics and its suitability for a differentiated experimental process analysis. For this purpose, mostly planning and shaping $[7,9,16,17]$ but also turning $[8,18]$ and special milling $[12,19]$ operations are used.

Henerichs et al. [8] used a longitudinal face turning process with different fibre orientations in order to investigate the tool wear behaviour of uncoated cutting tools as a function of the fibre cutting angle $\Phi$, which is defined as the angle between the fibre orientation and the cutting velocity direction. In accordance with previous studies [6, 13, 20,21], Henerichs et al. [8] identified a strong dependence of tool wear on the fibre cutting angle $\Phi$, where the most intense flank wear was measured for fibre cutting angles between $\Phi=30^{\circ}$ and $\Phi=90^{\circ}$, while for $\Phi=0^{\circ}$ and $\Phi=150^{\circ}$, only a small wearrelated change of the cutting edge geometry was observed. Henerichs et al. [8] explained these observations with significant differences in the chip formation process. Therefore, machining fibre cutting angles of $\Phi=30^{\circ}$ and $\Phi=60^{\circ}$ is associated with the overall highest thrust forces and the most intense elastic spring back of the CFRP material which in combination results in the overall highest tool loads and thus wear. According to Voss et al. [22], fibre cutting angles between $\Phi=0^{\circ}$ and $\Phi=90^{\circ}$ can be divided into three intervals, in which similar chip formation mechanisms and thus fundamental wear characteristics occur: $0^{\circ} \leq \Phi<15^{\circ}$ (interval I), $15^{\circ} \leq \Phi \leq 75^{\circ}$ (interval II), and $75^{\circ}<\Phi \leq 90^{\circ}$ (interval III). Sharma et al. [23] analysed the influence of the fibre cutting angle on the friction coefficient and the specific wear rate. It was found that, starting from $\Phi=0^{\circ}$, the friction coefficient and the specific wear rate increase for increasing fibre cutting angles. Furthermore, the authors identified the specific wear rate at $\Phi=90^{\circ}$ to be about three times higher than for $\Phi=0^{\circ}$. Nguyen et al. [12] performed edge trimming operations in order to analyse the land wear on the clearance face, the cutting edge radius, and the amount of worn tool material for a maximum cutting length of $l_{c u}=8 \mathrm{~m}$. For their experiments, four different fibre cutting angles $\left(\Phi=0^{\circ}, \Phi=45^{\circ}, \Phi=90^{\circ}, \Phi=135^{\circ}\right)$, two cutting velocities $\left(v_{c}=19.9 \mathrm{~m} / \mathrm{min}, v_{c}=119.7 \mathrm{~m} / \mathrm{min}\right)$, and a constant feed of $f=0.3 \mathrm{~m} / \mathrm{min}$ were used. Based on their results, the most intense flank wear is found for $\Phi=45^{\circ}$, while the largest cutting edge radius in the worn state is identified for $\Phi=90^{\circ}$.

In addition to the influence of the fibre cutting angle, different researchers have analysed the dependencies of tool wear on the tool geometry $[6,8,24]$ and the process parameters $[6,20,25]$. As a general conclusion, it was found that tool wear cannot be avoided, however, significantly reduced by an appropriate set of tool geometries and process parameters. In this context, Henerichs et al. [8] showed experimentally that occurring flank wear can be reduced clearly if cutting tools with a larger initial clearance angle are used. This is explained by the fact that increasing the clearance angle leads to smaller thrust forces and thus a reduced potential for mechanical wear. Caprino et al. [24] performed similar orthogonal machining experiments with glass fibre reinforced polymers (GFRP) at very low cutting speeds of $\mathrm{v}_{\mathrm{c}}=0.46 \mathrm{~m} / \mathrm{min}$ and came to the same conclusion. According to Caprino et al. [24], some evidence exists that the wear-related increase of the cutting force is mainly due to the variation of the thrust force as a consequence of severe flank wear. Besides the clearance angle, the authors analysed the influence of the depth of cut on tool wear progression and found that the flank wear and the process forces increase for higher depth of cut which is explained by the larger engagement of the cutting edge. Based on turning experiments, Ferreira et al. [26] analysed the influence of the cutting velocity on the flank wear and concluded that the flank wear progression is more intense for larger cutting velocities.

Moreover, different wear studies [26, 27] were performed in order to analyse the tool wear behaviour dependencies on tool materials and tool coatings. Based on an experimental study with different tool materials, Sakuma et al. [27] concluded that the wear rate decreases with increasing hardness of the tool material. In consequence of their high wear resistance, the predominant amount of researchers recommend cutting tools made of cemented carbide or polycrystalline diamond (PCD) $[28,29]$. In this context, cemented carbide tools are often coated with diamond or diamond-like coatings.

Progressive mechanical wear results in a continuously changing tool shape of the cutting edge which means that the tool/material interaction in the cutting zone and all associated process parameters are affected. As a consequence, numerous researchers have analysed the influence of progressive tool wear in machining of CFRP on changes in the chip formation mechanisms $[22,30,31]$, the process forces $[8,11$, $32]$, and the resulting workpiece quality $[8,32]$. According to Maegawa et al. [10], the wear-related change of the cutting edge is mainly characterised by an enlargement of the cutting edge rounding and a continuously decreasing clearance angle. Wang et al. [11] explained the increasing cutting edge radius due to wear with the absence of a work material stagnation zone in front of the cutting edge, which means that the corresponding tool region is constantly in contact with the abrasive carbon fibres. While the advancing bluntness of the tool has an influence on the chip formation mechanisms in front of the cutting edge, a decreasing clearance angle generally results in higher thrust forces as experimentally shown by Voss et al. [22].

In accordance with the research community, Ramulu [33] stated that the wear-related increase of process forces is associated with an increasing risk for process-related damages at 
the workpiece, e.g. delamination, fibre pull-out, and material cracking. Based on drilling operations with different tool geometries, Faraz et al. [34] analysed the influence of progressive tool wear on the delamination factor $F_{d}$ and found a clear correlation between the cutting edge radius and the bore hole entry/exit delamination. Henerichs et al. [35] performed bulging tests with single bore holes that are generated with drilling tools at different wear states. The authors identified an overall stiffness reduction up to $40 \%$ over a cutting length of $l_{c u l}=8 \mathrm{~m}$. Henerichs et al. [35] explained this observation with the material weakening of the bore hole entry/exit areas due to more intense material damages as a consequence of tool wear. Besides higher process forces, Chennakesavelu [36] describes a reduction of the cutting edge strength and the increasing process temperatures as further negative impacts of progressive tool wear in machining CFRP. Since especially for aerospace applications, the usage of liquid cooling are prohibited due to quality and automation requirements, the increasing process temperature is critical as it can lead to thermal damages, e.g. matrix degradation [37,38]. Consequently, different researchers investigated the applicability of residue-free cooling strategies such as compressed air $[39,40]$ and cryogenic cooling [4] with respect to the machining quality and the tool wear progression. Khanna et al. [4] performed drilling operations in CFRP material under dry and cryogenic environments and compared the thrust forces and the resulting hole quality. In this context, it was found that cryogenic cooling generally improves the surface finish of the bores and reduces the level of delamination.

By definition, mechanical wear only occurs within the contact zone of the cutting tool, which is limited to a small area in the close-up range of the cutting edge as shown in Fig. 1a. This operative and therefore wear-affected part of the cutting tool is defined as the tool's active micro-geometry. As schematically shown in Fig. 1b, the active micro-geometry is geometrically limited by the nominal material level ahead of the cutting edge represented by point $\mathrm{A}$ and the last tool/workpiece contact point $\mathrm{D}$ on the flank face. It has to be noted that the contact point $\mathrm{D}$ differs to the tool's foremost point $\mathrm{C}$ in feed direction due the elastic spring back of the CFRP material $[9,22]$. During the chip formation process, the CFRP material is compressed under the cutting edge. With advancing tool motion, this compressed area is relieved again after passing point $\mathrm{C}$ and the previously compressed CFRP material springs back elastically. Accordingly, the already cut CFRP material gets in contact with the flank face of the tool and causes mechanical wear. In Fig. $1 \mathrm{~b}$, the resulting contact area on the flank face due to elastic spring back is shown by the red line between points $\mathrm{C}$ and $\mathrm{D}$. According to Wang et al. [9] and Henerichs [41], the level of elastic spring back is the result of complex elastoplastic tool/ material interactions within the cutting region and thus highly influenced by the actual tool shape, the acting process forces, and the material properties including the fibre orientation and the actual material integrity.

\section{Initial situation}

By formulating an analytical force model to predict process forces in orthogonal machining CFRP for worn cutting tools, Voss et al. [22] proposed five wear parameters $\left(l_{\alpha}, l_{\gamma}, \gamma^{*}, \alpha^{*}\right.$, $b_{c}$ ) to approximate and simultaneously parametrise the active micro-geometry using a "straight line - ellipse - straight line" approach. For this purpose, the authors separate the entire active micro-geometry into the three regions as originally proposed by Zhang et al. [42]: region 1 (R1), region 2 (R2), and region 3 (R3). This separation is necessary in order to consider varying tool/material interactions along the contact zone. As schematically illustrated in Fig. 1c, R1 represents the contact area on the tool's rake face which is geometrically bounded by the points $\mathrm{A}$ and $\mathrm{B}$. R2 describes the cutting edge rounding between points $\mathrm{B}$ and $\mathrm{C}$, and $\mathrm{R} 3$ represents the contact zone on the tool's flank face between points C and D. As a first approximation, Voss et al. [22] assumed that the nearly straight shape of the rake and clearance faces remain with progressive tool wear; however, the corresponding rake and clearance angles change from $\gamma$ to $\gamma^{*}$ and from $\alpha$ to $\alpha^{*}$ due to non-uniform wear distributions in both regions. Although R2
Fig. 1 a Snapshot of a machining situation, b schematic illustration of the active micro-geometry, and c parameterisation of the active micro-geometry according to Voss et al. by using a "straight line - ellipse - straight line" approach [22]

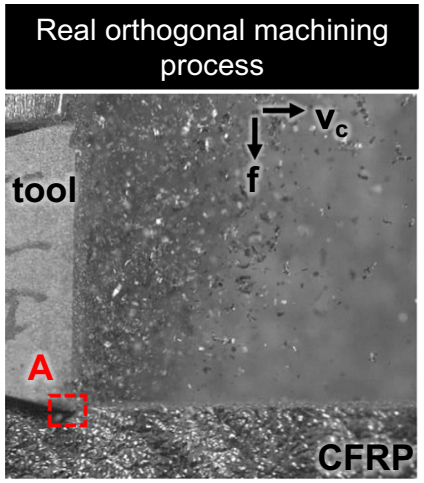

(a)

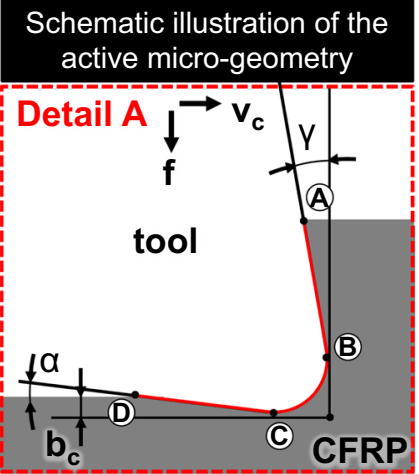

(b)

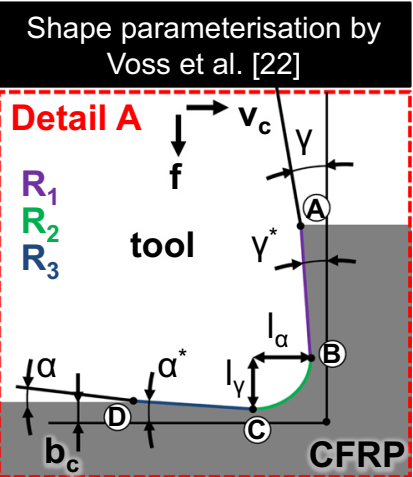

(c) 
is usually circular in the tool's new state, progressive tool wear causes an increasing asymmetric material removal with high volume loss on the tool's flank face as confirmed by numerous experimental studies $[8,12,31,43]$. In order to take this into account, Voss et al. [22] used an ellipse with its major and minor semi-axes $l_{\alpha}$ and $l_{\gamma}$ to approximate the tool shape in R2. The authors showed that this parameterisation approach is applicable to the new as well as to the worn state of the cutting tool. Finally, the authors defined the bouncing back height $b_{c}$, which is a measure for the elastic spring back of the CFRP material. In accordance with Fig. $1 \mathrm{c}, b_{c}$ is defined as the distance between points $\mathrm{D}$ and $\mathrm{C}$ measured in feed direction.

For model validation purposes, Voss et al. [22] performed orthogonal machining experiments, where the machining process was periodically interrupted at specific cutting length in order to determine the five wear parameters by means of epoxy filled imprints of the worn cutting edge. In this context, especially the determination of the last tool/material contact point $\mathrm{D}$ on the flank face was found to be highly error prone because of limitations of the imprints analysis procedure. The bouncing back height $b_{c}$ was only measurable for the heavily worn state of the cutting edge at the end of the experiments after a cutting length of $l_{c u}=40 \mathrm{~m}$. Instead, the authors used the following square root function to approximate the wearrelated trend of $b_{c}$ as a function of the actual cutting length $l_{\text {cut }}$ for lengths smaller than $l_{\text {cut }}=40 \mathrm{~m}$.

$b_{c}=b_{c 40 m} \cdot \sqrt{\frac{l_{c u t}}{40 m}}$

In (1), the parameter $b_{c 40 m}$ represents the measured bouncing back height in the heavily worn state after $l_{c u t}=40 \mathrm{~m}$. This function is only a rough approximation since it neglects the influences of the tool geometry and the fibre cutting angle on the wear-related change of the bouncing back height. Therefore, Voss et al. [22] highlighted in the outlook of their work the necessity of continuing fundamental wear analysis in order to improve the accuracy of the spring back data as well as to expand the gained process understanding on further sets of rake and clearance angles. Accurate data about the spring back behaviour of the CFRP material and its dependencies on the tool geometry, the fibre cutting angle, and the wear state are crucial for the tool manufacturing process as they help to understand the tool wear progression. This information can then be used to design tools with an enhanced wear resistance.

Therefore, this work focuses on performing a detailed experimental tool wear analysis in orthogonal machining UD CFRP material by taking a wide range of fibre orientations and tool geometries into account. In order to quantifiably track the wear-related change of the active micro-geometry as function of the cutting length, the previously introduced parameterisation via the five wear parameters $\left(l_{\alpha}, l_{\gamma}, \gamma^{*}, \alpha^{*}\right.$, $b_{c}$ ) is used. Machining operations with different sets of tool geometries and fibre orientations are periodically interrupted, and the five wear parameters are determined for each wear state by using 3D microscopy. In contrast to Voss et al. [22], no imprints but the original micro-geometry is considered for the evaluation of tool wear. In order to distinguish the operative part of the cutting edge, especially regarding the last tool/ material contact point $\mathrm{D}$ on the flank face, the cutting inserts are previously marked with lines perpendicular to the cutting edge by short pulsed laser ablation as explained in detail in Section 3.

The evaluated experimental data of tool wear progression in machining CFRP is valuable for further research which is focussing on the geometry-related minimisation of tool wear for cutting tools. Furthermore, this data set is used for the validation of an analytical wear model that will be presented in a future publication. Compared to prior publications, the experimental study is unique in terms of its level of detail and the wide range of tested tool geometries and fibre orientations. As a key advantage of the shape parameterisation, geometrical wear-related changes of the cutting edge can be discussed separately for the three regions. By drawing conclusions from the worn tool shapes on the theoretical material interactions during the machining process, a region-specific interpretation of the measured cutting and thrust forces is possible. In addition, the wear rate and the elastic spring back of the CFRP material are measured as functions of the cutting length and discussed in the context of their dependencies on the tool geometry and the fibre orientation.

\section{Materials and methods}

In this section, the experimental setup, the workpiece material, the tools, and the applied evaluation methods are explained in detail.

\subsection{Experimental setup}

In this experimental study, orthogonal machining experiments with UD CFRP material are conducted for a total cutting length of $l_{c u t}=35 \mathrm{~m}$. In accordance with the schematic illustration in Fig. 2, the orthogonal machining conditions are realised with a longitudinal face turning process. For this purpose, a CNC lathe type Okuma LB15-II is equipped with modified clamping jaws that allows the simultaneous clamping of three $120^{\circ}$ angular CFRP ring segments. Since all segments have one identical fibre orientation, this test rig allows non-interrupted orthogonal machining with different fibre cutting angles. In this work and as shown in Fig. 2, the fibre cutting angle is defined as the angle counter clockwise from the cutting velocity direction to the fibre axis. In total, CFRP ring specimens with four fibre cutting angles, namely, $\Phi=0^{\circ}, \Phi=30^{\circ}, \Phi=60^{\circ}$, and $\Phi=90^{\circ}$, are investigated. The 


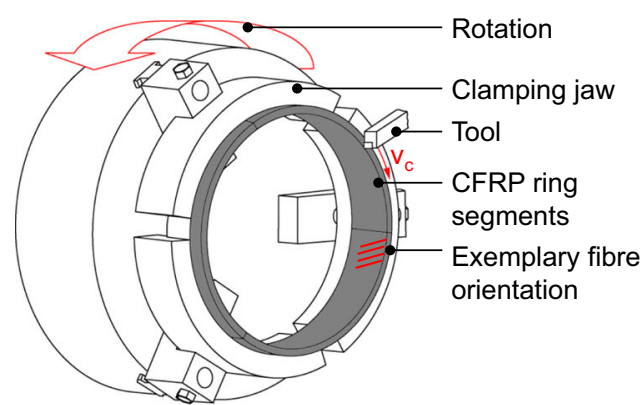

(a)

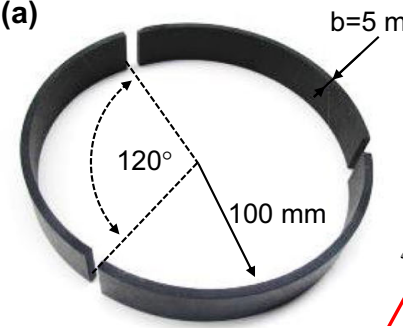

(b)

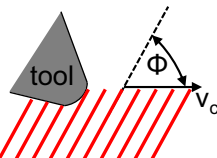

(c)

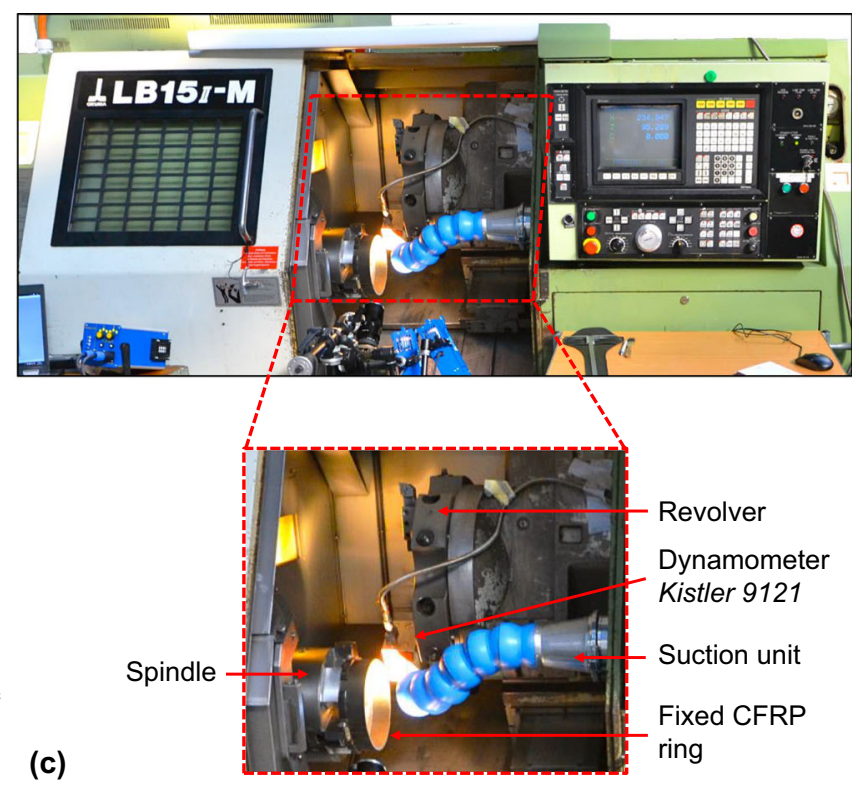

Fig. 2 a Schematic illustration of the clamped CFRP ring specimen and definition of the fibre cutting angle $\Phi$, $\mathbf{b}$ segmented CFRP ring specimen, and $\mathbf{c}$ experimental setup [8]

resulting CFRP ring specimens have a radius of $100 \mathrm{~mm}$, a width of $55 \mathrm{~mm}$, and a wall thickness of $b=5 \mathrm{~mm}$. The test rig configuration is explained in detail by Henerichs et al. [8]. A suction unit type AL-LO PowerUnit 120/400 is used for evacuation of powderlike CFRP particles, and a three axes dynamometer type Kistler 9121 is selected for measuring cutting and thrust forces during the machining operation.

\subsection{Material and cutting tools}

For the ring segments, UD CFRP material type M21/34\%/ UD194/IMA-12k is used. This material contains 34\% (by weight) epoxy-based, high performance matrix material type Hexply® M21 and 66\% intermediate modulus carbon fibres type IMA-12k. The carbon fibres are combined to rovings of 12,000 single fibres. An overview of mechanical and physical properties is shown in Table 1.

All turning experiments are conducted with a cutting velocity of $v_{c}=90 \mathrm{~m} / \mathrm{min}$, a feed rate of $f=0.03 \mathrm{~mm} / \mathrm{rev}$, and a width of cut of $a_{e}=5 \mathrm{~mm}$. The width of cut is defined by the wall thickness of the CFRP rings. The used cutting tools are uncoated

Table 1 Material properties M21/34\%/UD194/IMA-12k [44]

\begin{tabular}{|c|c|c|c|}
\hline Fibre mass & $194 \mathrm{~g} / \mathrm{m}^{2}$ & Tensile strength $^{*}$ & $3050 \mathrm{MPa}$ \\
\hline Laminate density & $1.58 \mathrm{~g} / \mathrm{cm}^{3}$ & Tensile modulus ${ }^{*}$ & $178 \mathrm{GPa}$ \\
\hline Glass trans. temp. & $195{ }^{\circ} \mathrm{C}$ & Comp. strength ${ }^{* *}$ & $1500 \mathrm{MPa}$ \\
\hline Fibre volume & $59.2 \%$ & Comp. modulus ${ }^{* *}$ & $146 \mathrm{GPa}$ \\
\hline
\end{tabular}

* Standard EN 6032, ${ }^{* *}$ standard EN $2561 \mathrm{~B}$ cutting inserts (grade: H13A, geometry: CCMW09T304) made out of a tungsten carbide substrate. These tool geometries are customised by additional grinding operations in order to provide specific sets of initial rake and clearance angles. Table 2 gives an overview of all tested combinations of rake and clearance angles with the corresponding identification letters of the cutting inserts that are used throughout this work. According to Table 2, a reduced number of tool geometries is tested for $\Phi=30^{\circ}$ due to a limited amount of CFRP material with this fibre orientation. Furthermore, no machining experiments are conducted for the combination $\gamma=30^{\circ}$ and $\alpha=21^{\circ}$ since preliminary tests with this tool geometry showed a high risk for process instabilities and breakouts at the cutting edge. The initial cutting edge radius for all tested tool geometries is $7 \mu \mathrm{m}$.

For all tested tool geometries in Table 2, the flank face of the cutting insert is marked with a short pulsed Yb-laser type $I P G$ YLP-HP. The application of the laser process and the wear evaluation procedure are explained in detail by Seeholzer et al. [45]. Hence, laser marks parallel and perpendicular to the cutting edge are generated on the flank face of the cutting inserts resulting in a grid mark. The lines parallel to the cutting edge have a distance of $100 \mu \mathrm{m}$ to each other, and the corresponding perpendicular lines are arranged in intervals of $500 \mu \mathrm{m}$ as shown in Fig. 3. The laser-affected zone is only related to a very thin top-layer of the cutting tool and vanishes when getting in contact with the bounced back composite material. This allows the optical detection of the last tool/ material contact point on the flank face. Preliminary tests with laser marked cutting inserts did not show any influences of such laser modifications on both, the cutting conditions and the wear behaviour of the micro-geometry. 
Table 2 Tested cutting insert geometries (H13A, CCMW09T304) and fibre cutting angles

\begin{tabular}{|c|c|c|c|c|c|c|c|c|}
\hline Tool geometry & $\mathrm{E}$ & $\mathrm{H}$ & I & $\mathrm{J}$ & $\mathrm{L}$ & M & $\mathrm{N}$ & $\mathrm{O}$ \\
\hline Rake angle $\gamma\left[{ }^{\circ}\right]$ & 10 & 10 & 10 & 20 & 20 & 20 & 30 & 30 \\
\hline Clearance angle $\alpha\left[^{\circ}\right]$ & 7 & 14 & 21 & 7 & 14 & 21 & 7 & 14 \\
\hline Abbreviation & $\mathrm{E}(10,7)$ & $\mathrm{H}(10,14)$ & I $(10,21)$ & $\mathrm{J}(20,7)$ & $\mathrm{L}(20,14)$ & $M(20,21)$ & $\mathrm{N}(30,7)$ & $\mathrm{O}(30,14)$ \\
\hline \multicolumn{9}{|c|}{ Tested fibre cutting angle } \\
\hline$\Phi=0^{\circ}$ & $\checkmark$ & $\checkmark$ & $\checkmark$ & $\checkmark$ & $\checkmark$ & $\checkmark$ & $\checkmark$ & $\checkmark$ \\
\hline$\Phi=30^{\circ}$ & & $\checkmark$ & & $\checkmark$ & $\checkmark$ & $\checkmark$ & $\checkmark$ & \\
\hline$\Phi=60^{\circ}$ & $\checkmark$ & $\checkmark$ & $\checkmark$ & $\checkmark$ & $\checkmark$ & $\checkmark$ & $\checkmark$ & $\checkmark$ \\
\hline$\Phi=90^{\circ}$ & $\checkmark$ & $\checkmark$ & $\checkmark$ & $\checkmark$ & $\checkmark$ & $\checkmark$ & $\checkmark$ & $\checkmark$ \\
\hline
\end{tabular}

\subsection{Tool wear evaluation}

During the turning operation, the machining process with a total cutting length of $l_{c u l}=35 \mathrm{~m}$ is periodically interrupted at specific cutting lengths, and the actual cutting edge microgeometry is acquired via 3D microscopy. In total, six analysis steps at $l_{\text {cut }}=0 \mathrm{~m}, l_{\text {cut }}=5 \mathrm{~m}, l_{\text {cut }}=10 \mathrm{~m}, l_{\text {cul }}=15 \mathrm{~m}, l_{\text {cut }}=20 \mathrm{~m}$, and $l_{\text {cul }}=35 \mathrm{~m}$ are considered for the wear analysis, where $l_{\text {cut }}=0 \mathrm{~m}$ describes the initial state of the cutting tool. For each wear state, the respective active micro-geometry by means of the wear parameters $l_{\alpha}, l_{\gamma}, \gamma^{*}$, and $\alpha^{*}$ and the bouncing back height $b_{c}$ are evaluated. This enables a wear-dependent trend analysis for all parameters as functions of the tool geometry and the fibre cutting angle with respect to the six analysing steps.

As shown in Fig. 4, the evaluation of the wear parameter is done by means of representative 2D profiles, which are determined based on the acquired 3D data sets of the entire cutting edge. These 2D profiles are obtained in the middle of the cutting insert and are averaged over a width of $50 \mu \mathrm{m}$. The location of the contact point $\mathrm{D}$ is evaluated optically based on the laser-produced marking line perpendicular to the middle of the cutting edge. Since the cutting velocity and feed directions are known for each tool geometry at each wear state, the contact points $\mathrm{B}$ and $\mathrm{C}$ can always be evaluated as being the foremost points in both directions. Once the contact points D

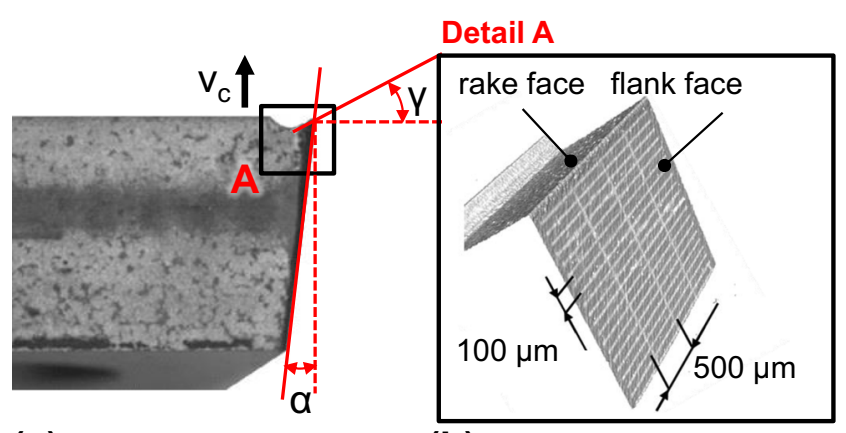

(a)

(b)

Fig. 3 Exemplary cutting insert; a side view and $\mathbf{b}$ oblique view including laser modifications on the flank face [45] and $\mathrm{C}$ are known, the corresponding friction length on the tool's flank face $l_{f r}$ is measured as the direct distance between these two points as shown in Fig. 4. Once the bouncing back height and the friction length are known, the corresponding clearance angle can be determined indirectly as follows:

$\alpha^{*}=\sin ^{-1}\left(\frac{b_{c}}{l_{f r}}\right)$

In R2, the semi-axes $l_{\alpha}$ and $l_{\gamma}$ of the ellipse are determined as the direct distances between points $\mathrm{B}$ and $\mathrm{C}$ in cutting velocity and feed direction respectively.

In the applied test rig presented in Section 3.1, the annular material is re-processed by each spindle rotation. Consequently, the CFRP material is removed layer by layer, where the bouncing back height in R3 results in a difference between the programmed and the actual depth of cut. Assuming that the difference in bouncing back height between two consecutive spindle rotations is negligible, the actual depth of cut $a_{c}$ can be calculated as follows:

$a_{c}=f+b_{c}$

Since the distance between points $\mathrm{A}$ and $\mathrm{C}$ in feed direction equals to the actual depth of cut, the location of the contact point $\mathrm{A}$ on the rake face can be determined by using the location of point $\mathrm{C}$ and (3).

In machining CFRP, occurring tool material loss due to wear is not equally distributed over the operative part of the cutting edge due to irregular distributions of contact pressure and sliding velocities. This means that the removed tool material per metre cutting length varies significantly along the active micro-geometry, where especially the tool section close to the cutting edge suffers intense volume loss. In this work, the material loss at the cutting tool is quantified by using the averaged profiles in the middle of the cutting inserts as already explained for the evaluation of the five wear parameters. For this purpose, the parameter $A_{w}$ is defined representing the cross-sectional area between a worn and a not worn cutting 


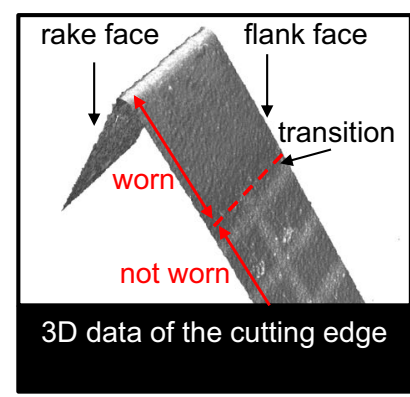

(a)

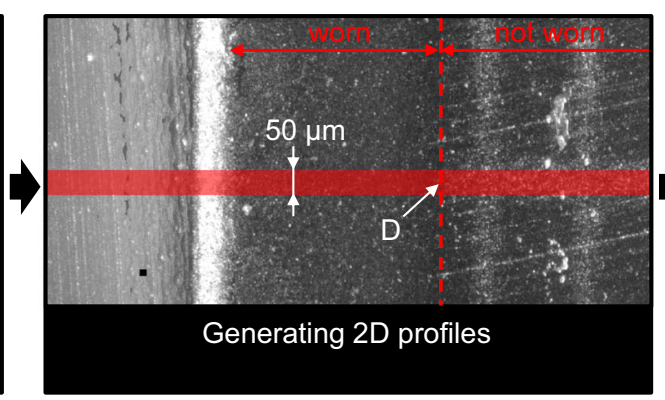

(b)

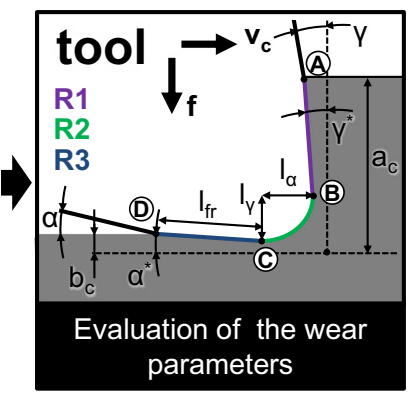

(c)

Fig. 4 Evaluation procedure for the wear parameters $l_{\alpha}, l_{\gamma}, \gamma^{*}, \alpha^{*}$, and $b_{c}$ and the friction length $l_{f r}$; a $3 \mathrm{D}$ data set, $\mathbf{b}$ generating $2 \mathrm{D}$ profiles, and $\mathbf{c}$ evaluation of $2 \mathrm{D}$ profiles

edge profile that both are measured at the same position in the middle of the cutting insert. As a first approximation, the corresponding volume loss of the entire cutting tool can be determined by multiplying the cross-sectional area $A_{w}$ with the cutting width $b$. Since instead of the 3D data set of the entire tool geometry only the 2D cutting edge profiles are used, the therefore calculated volume loss represents a first approximation with some degree of uncertainty. This uncertainty depends on how representative the $2 \mathrm{D}$ profile in the middle of the cutting insert is compared to the remaining cutting edge.

Against this background, Fig. 5 (left) shows the contact situation between a cutting insert and a CFRP ring segment, where the contact length of the cutting edge in y-direction corresponds to the cutting width $b$ of the orthogonal machining operation. Using the example of tool geometry E (10/7), the enlarged picture in Fig. 5 (left) shows a side view on the 3D data set of the entire cutting edge after orthogonal machining UD CFRP material with a fibre cutting angle of $\Phi=90^{\circ}$ at a cutting length of $l_{c u l}=35 \mathrm{~m}$. Based on the $3 \mathrm{D}$ data set of the worn cutting edge, 2D profiles are determined at different positions along the cutting width. The superposition of five representative cutting edge profiles is shown in Fig. 5 (right), where each profile is averaged over a width of $50 \mu \mathrm{m}$. Generally, two regions with different properties are detected, which in the following are called the transition region and the steady-state region. The steady-state region covers about $80 \%$ of the cutting width. According to Fig. 5 (right), the $2 \mathrm{D}$ profiles of the cutting edge measured within the steady-state region are almost identical. This means that tool wear in the steady-state region is nearly uniformly distributed along the cutting edge and thus can be sufficiently represented by one single cutting edge measurement. The transition regions describe the change from the worn to the not worn cutting edge at the border areas of the cutting width. According to Fig. 5 (right), these transition areas are characterised by overall less volume loss. In consequence, the multiplication of the cross-sectional area $A_{w}$ and the cutting width $b$ results in a slightly too high volume loss but represents a reasonable first approximation with a significant lower measurement effort.

\section{Fundamental machining mechanics in orthogonal machining UD CFRP}

As an essential prerequisite for the evaluation and the interpretation of the experimental results following in Section 5, this chapter provides a short summary about the chip formation mechanisms in orthogonal machining CFRP and their dependencies on the tool geometry and the fibre cutting angle.
Fig. 5 Exemplary wear behaviour along the cutting edge. a Differentiation of transition and steady-state regions and $\mathbf{b}$ superposition of cutting edge profiles along the contact length of the cutting edge $\left(v_{c}=90 \mathrm{~m} / \mathrm{min}\right.$, $f=0.03 \mathrm{~mm} / \mathrm{rev}$ )

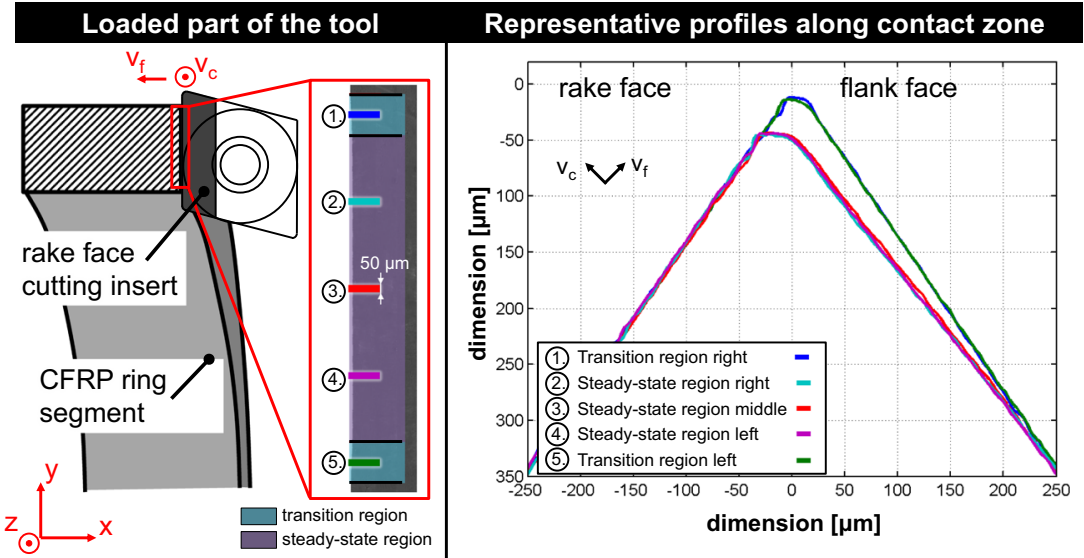

(a) (b) 
Due to the material-specific heterogeneity and anisotropy, the machining mechanics in the three contact regions R1, R2, and R3 vary with respect to the fibre cutting angle. Furthermore, the resulting tool/fibre interactions in the contact zone are strongly influenced by the tool shape and acting forces. Depending on the resulting loading situation defined by the fibre orientation and the tool geometry, the CFRP material in the contact zone fails due to buckling, bending, and shear loads or a superposition of them. Despite this fact, Voss et al. [22] showed that the range of fibre cutting angle $0^{\circ} \leq \Phi \leq 90^{\circ}$ can be separated into three intervals with similar loading situations and chip formation mechanisms and therefore comparable wear characteristics. These intervals are $0^{\circ} \leq \Phi<15^{\circ}$ (interval I), $15^{\circ} \leq \Phi \leq 75^{\circ}$ (interval II), and $75^{\circ}<\Phi \leq 90^{\circ}$ (interval III) and are schematically shown in Fig. 6. In the following subsections 4.1-4.3, the interval-specific contact situations between the tool and the CFRP material, the resulting tool loads and the chip formation mechanisms are discussed with respect to tool wear.

During the machining operation, the CFRP material in front of the cutting edge is loaded in effective cutting direction, which is defined by the vectorial addition of the cutting and feed motions. Based on the selected process parameters mentioned in Section 3.2, the percentage share of the feed motion to the effective cutting velocity is negligibly small, which means that the effective cutting direction is almost identical to the cutting velocity direction. However, not only the effective cutting direction but also the actual shape of the active micro-geometry has to be considered since it defines the contact path of the compressed CFRP material in the contact zone. As a result, the shape of the active micro-geometry depends on the initial tool geometry and the wear state of the cutting insert.

\subsection{Contact situation: Interval I $\left(0^{\circ} \leq \Phi<15^{\circ}\right)$}

In interval I, the carbon fibres are mainly oriented in cutting velocity direction. In case of $\Phi=0^{\circ}$, the fibres are parallel to the cutting velocity direction as shown in Fig. 6a. According to Voss et al. [22], chip formation in machining UD CFRP with a fibre cutting angle in interval $I$ is the result of periodical material failure in front of the cutting edge due to material loads generated in R1 and R2. The loading situation in R1 is comparable to an oblique plane, which compresses the CFRP material in front of it, whereas the level of obliqueness is defined by the rake angle of the cutting tool. As stated by Rummenhöller [6], the choice of the rake angle has a major influence on the resulting loading situation in front of R1.

A small rake angle leads to a contact situation where the carbon fibres are axially compressed, while lateral sliding of the fibre ends along the rake face is mostly prevented due to the steep slope and the high stiffness of the fibres. In consequence of their geometrical shape as slender beams, the axially compressed fibres in front of R1 fail by micro-buckling, which in accordance with Xu and Reifsnider [46], describes a structural failure mode of fibre bundles due to a simultaneous buckling action. Since the compressed fibres fail at a certain distance from the cutting tool, micro-buckling is associated with a short-term load relaxation and thus leads to periodic tool loads in R1. In contrast, a large rake angle enables the compressed carbon fibres in front of R 1 to evade partially the axial compression by sliding along the rake face. According to Rummenhöller [6], the increasing lateral deflection of carbon fibres in contrary feed direction results in a peel stress situation, where the intermediate fibre area and thus the matrix material are loaded by shear stress. By exceeding the shear strength of either the matrix or the fibre/matrix bonding, an advancing interlaminar crack is released. The crack propagation allows the already loaded fibres to slide along the rake face until the most bent fibres fail due to exceeding tensile stresses. Subsequently, the advancing interlaminar crack is complemented with a transverse fibre crack that propagates in direction of the top surface and thus allows the formation of chip blocks containing several fibre fragments.

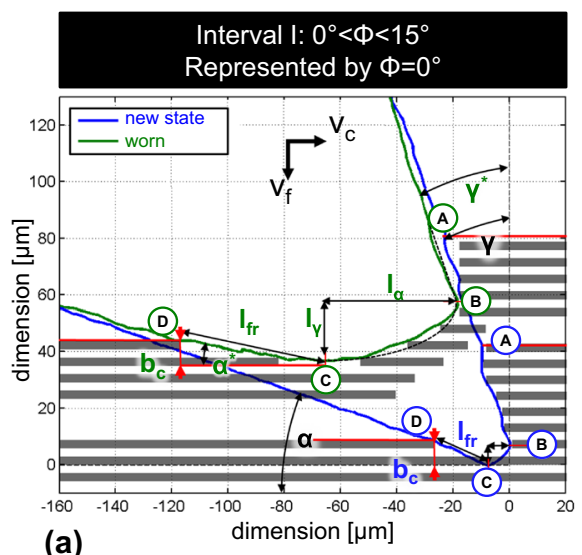

(a)

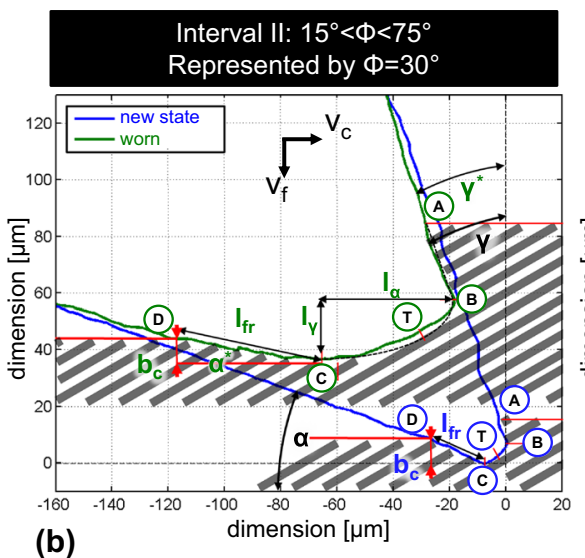

(b)

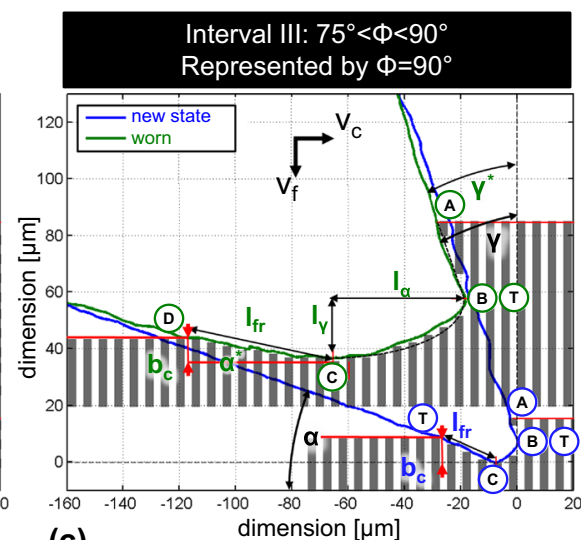

(c)
Fig. 6 Schematic illustrations of tool/material contact situation for a new and worn tool in machining UD CFRP with different fibre cutting angles: a $\Phi=0^{\circ}$, b $\Phi=30^{\circ}$, and $\mathbf{c} \Phi=90^{\circ}$; initial rake and clearance angles: $\gamma, \alpha$; wear parameters $l_{\alpha}, l_{\gamma}, \gamma^{*}, \alpha^{*}$, and $b_{c}$; friction length: $l_{f r}$; contact points A, $\mathrm{B}, \mathrm{C}$, and $\mathrm{D}$; first tool/fibre contact point: $\mathrm{T}$; cutting velocity: $v_{c}$; feed velocity: $v_{f}$ 
In interval $\mathrm{I}$, the curved shape of $\mathrm{R} 2$ results in a loading situation, where the carbon fibres are axially compressed in cutting velocity direction, while they are simultaneously pressed underneath the cutting tool in feed direction. Therefore, the ratio between compression and bending depends on the current tool/fibre contact situation and thus on the actual shape and size of R2. Close to point $\mathrm{B}$, the loading situation is predominated by axial compression, which leads to a material separation by micro-buckling. However, the closer the tool/fibre contact position moves to point $\mathrm{C}$, the more the fibres are loaded by lateral bending deformations in feed direction due to the curved shape of R2. This superimposed bending allows some compressed fibres close to point $\mathrm{C}$ to dive underneath the cutting edge. While diving under the cutting edge, these bent fibres continuously rub along the tool shape under high contact pressure as well as a high relative velocity leading to extensive mechanical wear. According to Usui and Shirakashi [47], material loss due to wear is more intensive the higher the contact pressure and the relative velocity are. As a result, the strongest mechanical wear occurs in $\mathrm{R} 2$ close to point $\mathrm{C}$.

Since the material compression in $\mathrm{R} 2$ is partially elastic, the compressed material tends to spring back after passing point $\mathrm{C}$ and hence gets in contact with the flank face where it causes friction. The actual area of contact depends on the clearance angle and the magnitude of elastic spring back. Within this contact region, the bounced back CFRP material rubs along the flank face, which in combination with the abrasive carbon fibres and the high contact pressure causes material removal due to mechanical wear. Due to a stepwise reduction of the induced elastic deformations, the resulting contact pressure in $\mathrm{R} 3$ decreases form point $\mathrm{C}$ in direction to point $\mathrm{D}$. The resulting non-uniform tool load favours a non-uniform material removal in R3 as schematically shown in Fig. 6 a.

\subsection{Contact situation: Interval II $\left(15^{\circ}<\Phi<75^{\circ}\right)$}

Figure $6 \mathrm{~b}$ illustrates the contact situation in interval II with a representative fibre cutting angle of $\Phi=30^{\circ}$, where the carbon fibres in front of the cutting edge are rotated counter clockwise to the cutting velocity direction. The first tool/fibre contact point is defined to be $\mathrm{T}$, which depends on the actual shape of R2 and varies with respect to the different fibre cutting angles in interval II.

Beginning at point $\mathrm{T}$, the carbon fibres in front of the cutting edge are bent in effective cutting direction, while they simultaneously slide along R2 in contrary cutting direction during the machining operation. According to Qi et al. [48], these loaded carbon fibres fail at their inner face by exceeding tensile strength as a consequence of the forced bending deformation. After an initial fibre crack in the immediate vicinity of the contact point $\mathrm{T}$, the just detached fibre end is pushed upwards and gets in contact with R1, while the matrix material, which is connected to the adjacent fibres, is loaded by shear. According to Zhang et al. [42], this loaded matrix material fails by interlaminar shear fracture and subsequently allows for lateral shearing-off of adjacent fibre layers in front of R1. Meanwhile, the lower part of the cut carbon fibre is still connected to the remaining workpiece material and thus gets further bent and pressed in feed motion due to the continuing cutting motion, while it is still in contact with R2. Shortly after, this further bent carbon fibre fails again, once the fibre's tensile strength is exceeded at the location of maximum curvature in consequence of the bending deflection caused by the tool motion [22]. However, the location of this second fibre separation is different to that of the initial one in contact point $\mathrm{D}$, which means that the second crack still occurs in R2 but closer to point C. Subsequently, the just described bending and cracking mechanism in terms of further bending is repeated until either the remaining fibre deflection is too small for an additional crack or the last fibre fracture occurs already underneath the cutting edge. Consequently, the actual number of potential further cracks depends on the initial contact point $T$ and the shape and size of R2, which changes with progressive tool wear. Analogous to interval I, the material compression in R2 results in additional frictional contact on the flank face, which is represented by R3. In this context, the dependencies described above for interval I are also valid for interval II.

\subsection{Contact situation: Interval III $\left(75^{\circ}<\Phi \leq 90^{\circ}\right)$}

Figure $6 \mathrm{c}$ illustrates the contact situation in interval III with a representative fibre cutting angle of $\Phi=90^{\circ}$, where the carbon fibres in front of the cutting edge are oriented perpendicular to the cutting velocity direction. Accordingly, the first tool/fibre contact point $\mathrm{T}$ is identical to the foremost point $\mathrm{B}$ in cutting velocity direction. This means that in contrast to interval II, the point $\mathrm{T}$ remains fixed and does not continuously shift towards point $\mathrm{C}$ due to an increasing cutting edge rounding in $\mathrm{R} 2$. Consequently, the first tool/fibre contact point in R2 is not influenced by the wear state of the cutting insert.

During the machining operation, the carbon fibres in front of the cutting edge at point $\mathrm{B}$ are bent in cutting velocity direction, while they are supported by the remaining CFRP material ahead of the cutting edge. According to Hetényi [49], this support of the residual CFRP material acts like an elastic foundation for the bent fibre and has an important influence on the fibre's bending deflection. Supported by the elastic foundation, the bent fibres fail in the vicinity of the tool/fibre contact point B. According to Voss et al. [22], this initial fibre separation is due to high and focussed compressive loads and arises as soon as the compressive strength of the fibre is exceeded. While the carbon fibres transversally deflect in consequence of bending, the intermediate matrix material is loaded by a combination of compression and shear. If the shear strength of either the matrix or the fibre/matrix bonding is 
exceeded, this results in interlaminar material cracks ahead of the tool's contact area [5]. These interlaminar cracks are oriented in opposite feed direction and can reach up to the surface level of the uncut CFRP material. After an initial fibre crack close to point $\mathrm{B}$, the free end of the just cut carbon fibre is pushed upwards and therefore evacuated over the rake face. Since these free fibre ends are no longer connected to the remaining material under the cutting edge, the combination of the cutting motion and the previously induced interlaminar material cracks leads to the formation of small chip blocks containing several fibre fragments. Meanwhile, the lower part of the just cut carbon fibre is further bent in the direction of the cutting velocity resulting in the repetitive bending and cracking mechanism as already described in interval II. The spring back effects on the flank face are comparable to those in intervals I and II.

\section{Experimental results and discussion}

In this section, the experimental results for the five wear parameters $\left(l_{\alpha}, l_{\gamma}, \gamma^{*}, \alpha^{*}, b_{c}\right)$, the friction length $l_{f r}$, the twodimensional wear rate $A_{w}$, and the corresponding cutting and thrust forces are presented. The presented data is accompanied by a detailed interpretation of the experimental results using the fundamental machining mechanics described in Section 4. Furthermore, the interrelation between the wear-related change of the active micro-geometry and the measured process forces is discussed under consideration of the fibre cutting angle and the initial tool geometry.

The results are divided into the three Subsections 5.1, 5.2, and 5.3 with respect to the three intervals I, II, and III. Each subsection contains two main plots, where the first one shows a summary of the evaluated wear parameters $\left(l_{\alpha}, l_{\gamma}, \gamma^{*}, \alpha^{*}, b_{c}\right)$ and the friction length $l_{f r}$ as functions of the cutting length for all tested combinations of rake and clearance angles according to Table 2. For the sake of clarity, these results are further subdivided into groups of the three tested rake angles: $\gamma=10^{\circ}, \gamma=20^{\circ}$, and $\gamma=30^{\circ}$. For each rake angle, the evaluated trends of the parameters $\left(l_{\alpha}, l_{\gamma}, \gamma^{*}, \alpha^{*}, b_{c}, l_{f r}\right)$ are shown as functions of the tested clearance angles and the cutting length. In addition to the parameter trends, the superposition of the corresponding averaged 2D tool profiles are outlined in separate lines. According to the tool evaluation introduced in Section 3.3, each wear parameter trend line is based on five supporting points defined by the wear analysis steps at $l_{c u t}=5$ $\mathrm{m}, l_{\text {cut }}=10 \mathrm{~m}, l_{\text {cut }}=15 \mathrm{~m}, l_{\text {cut }}=20 \mathrm{~m}$, and $l_{\text {cut }}=35 \mathrm{~m}$. In contrast to $b_{c}$ and $l_{f r}$, the parameters $l_{\alpha}, l_{\gamma}, \gamma^{*}$, and $\alpha^{*}$ are also known in the not worn (initial) tool state at $l_{c u t}=0 \mathrm{~m}$ and thus are additionally plotted. The second main plot in each subsection reveals the measured cutting and thrust forces as functions of the cutting length based on the same five supporting points.

Finally, Subsection 5.4 shows the experimental results for the wear rate $A_{w}$.

\subsection{Results: Interval I $\left(0^{\circ} \leq \Phi<15^{\circ}\right)$}

Representative for interval I, the wear-related change of the tools active micro-geometry is analysed in terms of the fibre cutting angle $\Phi=0^{\circ}$ for a total cutting length of $l_{c u t}=35 \mathrm{~m}$. While the wear-related trends of the five wear parameters $\left(l_{\alpha}, l_{\gamma}, \gamma^{*}, \alpha^{*}, b_{c}\right)$ and the friction length $l_{f r}$ are shown in Fig. 7, Fig. 8 reveals the corresponding cutting and thrust forces.

R1: As shown in Fig. 7, the wear trend of $\gamma^{*}$ is highly dependent on the initial rake angle, while the influence of the initial clearance angle is nearly negligible. The latter is explained by the fact that the clearance angle is not geometrically related to the shape of R1 and thus does not directly affect the corresponding tool/fibre interactions on the rake face. The $2 \mathrm{D}$ cutting edge profiles of the tool geometries E (10/7), H (10/14), and $\mathrm{I}(10 / 21)$ with initial rake angles of $\gamma=10$ show appreciable material removal in R1 due to wear, especially close to the foremost point $\mathrm{B}$ in cutting velocity direction. Furthermore, it can be seen that from point B onwards, the level of material removal in $\mathrm{R} 1$ decreases along the rake face in direction to point A. Consequently, occurring tool wear in R1 results in a reduction of the rake angle, which corresponds to the evaluated trends of $\gamma^{*}$. For these three tool geometries, the wearrelated reduction of the rake angle occurs very quickly and $\gamma^{*}$ equals to zero in any case after a cutting length of $l_{c u t}=10 \mathrm{~m}$. Subsequently, this value remains until the end of the experiment at $l_{\text {cut }}=35 \mathrm{~m}$. Moreover, an initial rake angle of $\gamma=10^{\circ}$ is rather small, which in accordance with Section 4.1 means that the fibres in front of R1 experience high concentrated compressive loads until failing due to micro-buckling. During the buckling action, the intact fibres and the broken fibre fragments are alternately pressed against the surface of R1, while they are simultaneously pushed in opposite feed direction causing mechanical wear.

In contrast to the tool geometries $\mathrm{E}(10 / 7), \mathrm{H}(10 / 14)$, and I (10/21), Fig. 7 reveals that the cutting edge profiles of tool geometries J (20/7), L (20/14), and M (20/14) with a larger initial rake angle of $\gamma=20^{\circ}$ show considerably less tool wear in R1. Consistently, the corresponding trends of $\gamma^{*}$ show a clearly less pronounced reduction of the rake angle with increasing

Fig. 7 Wear evaluation for UD CFRP material with $\Phi=0^{\circ}$; trends of the wear parameters $\left(l_{\alpha}, l_{\gamma}, \gamma^{*}, \alpha^{*}, b_{c}\right)$; and the friction length $l_{f r}$ as function of the cutting length for all tested sets of rake and clearance angles $\left(v_{c}=90\right.$ $\mathrm{m} / \mathrm{min}, f=0.03 \mathrm{~mm} / \mathrm{rev}$ ) 


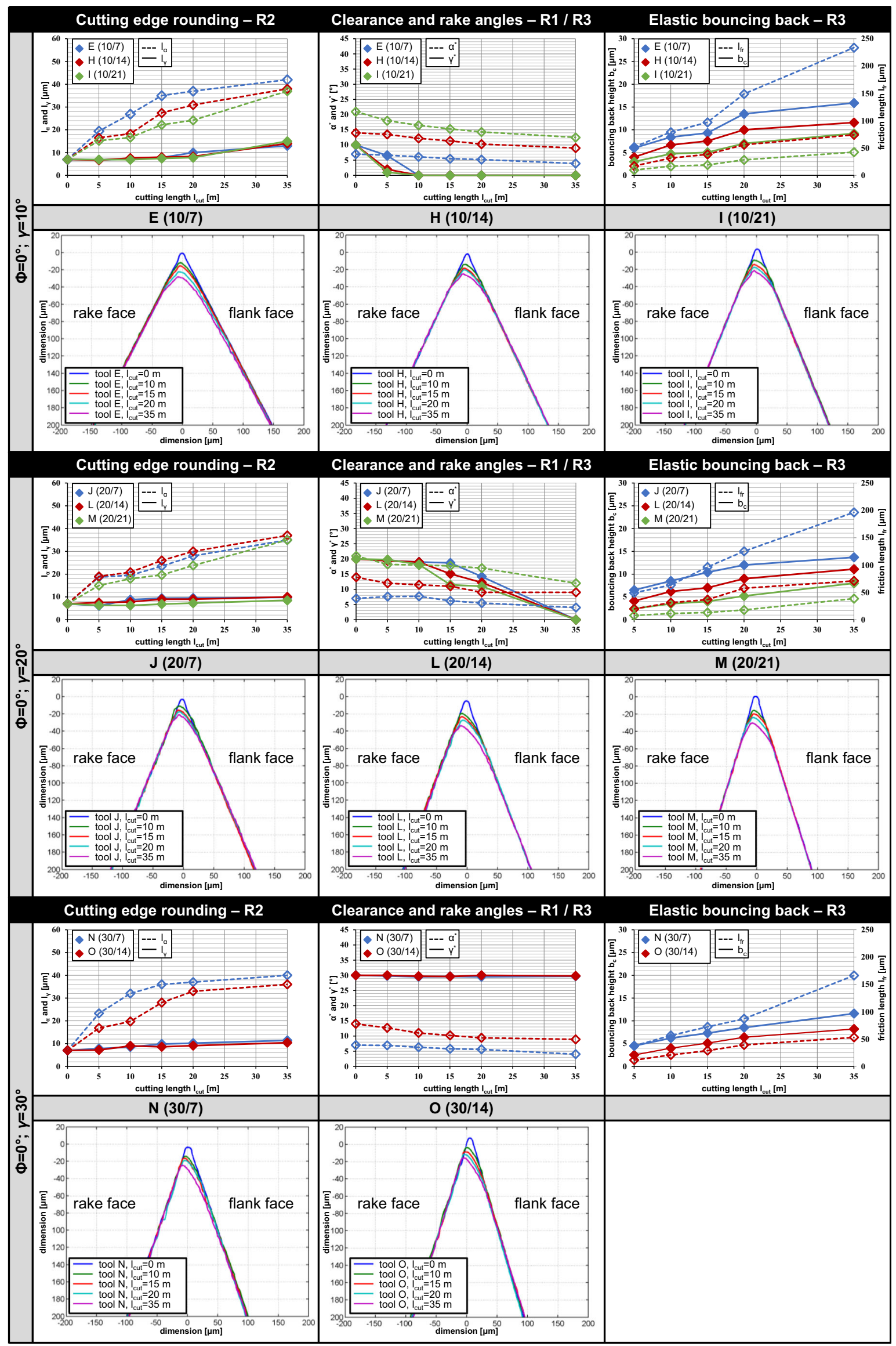




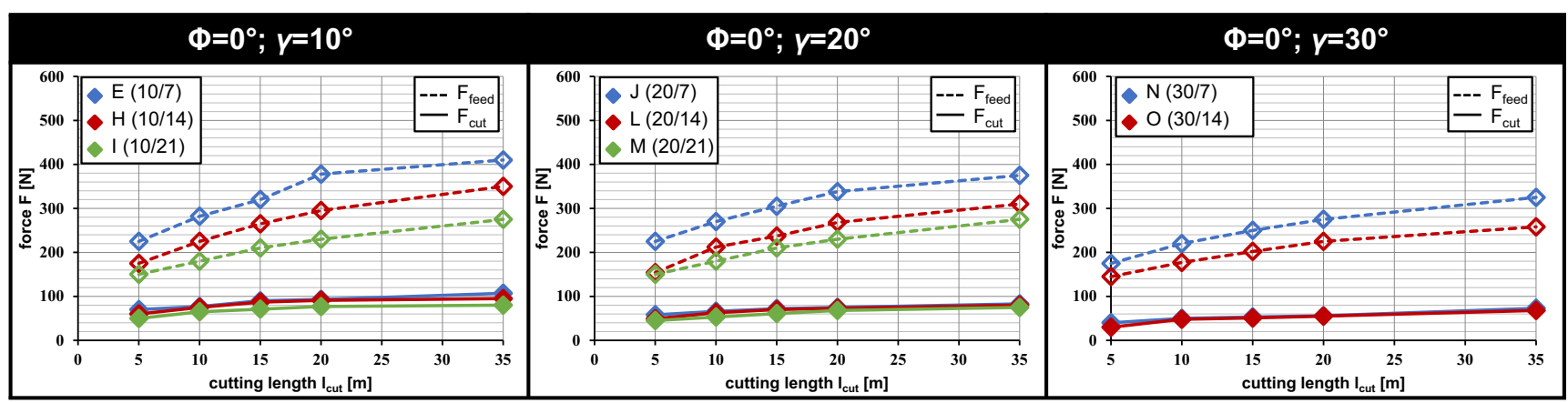

Fig. 8 Cutting and thrust forces in machining UD CFRP material with $\Phi=0^{\circ}\left(v_{c}=90 \mathrm{~m} / \mathrm{min}, f=0.03 \mathrm{~mm} / \mathrm{rev}\right)$

cutting length which means that the rake face experiences less material removal caused by wear. According to Fig. 7, the value of $\gamma^{*}$ equals to zero only after a cutting length somewhere between $l_{\text {cut }}=20 \mathrm{~m}$ and $l_{\text {cut }}=35 \mathrm{~m}$. By referring to Section 4.1, this observation is explained with a changing chip formation mechanism due to a larger initial rake angle of $\gamma=20^{\circ}$. When increasing the rake angle from $\gamma=10^{\circ}$ to $\gamma=20^{\circ}$, chip formation by peeling becomes increasingly more important and hence successively replaces buckling as predominant fibre failure mechanism. Chip formation by peeling is characterised by a higher energy efficiency which means that lower separation forces are needed. This corresponds to the measured process forces in Fig. 8, where the cutting forces for tool geometries with an initial rake angle of $\gamma=20^{\circ}$ are clearly lower than for tool geometries with an initial rake angle of $\gamma=10^{\circ}$. A reduction of cutting force means in turn that the overall tool load in R1 and thus the risk for wear-related material removal is reduced. This corresponds to the findings of $\gamma^{*}$ and the worn cutting edge profiles mentioned above. Although for the new state of these tool geometries, chip formation is predominated by peeling, the wear-related reduction of $\gamma^{*}$ means that with increasing tool wear, buckling must gain again of importance as material failure mode. However, the effect of the changing cutting mechanism on cutting forces is not directly visible in Fig. 8, since with progressive tool wear, the cutting force components in R1 are superimposed and increasingly dominated by those generated in the heavily worn regions $\mathrm{R} 2$ and $\mathrm{R} 3$ as shown in the following.

According to the cutting edge profiles shown in Fig. 7, the tool geometries $\mathrm{N}(30 / 7)$ and $\mathrm{O}(30 / 14)$ with an initial rake angle of $\gamma=30^{\circ}$ show no appreciable changes of tool shape in R1. Consistently, the rake angle does not change with progressive tool wear which means that the initial and worn rake angles are comparable $\gamma^{*}=\gamma$. In accordance with the explanation above, a further increase of the initial rake angle from $\gamma=20^{\circ}$ to $\gamma=30^{\circ}$ means that chip formation by peeling becomes even more dominant, while the tendency for buckling is further reduced. Consequently, the required separation force for initiating chip formation is also reduced, which results in lower cutting forces as shown in Fig. 8 and therefore reduced wear effects.
R2: According to Fig. 7 and independent of the tested tool geometries, the wear parameter $l_{\alpha}$ always increases significantly faster than $l_{\gamma}$ resulting in a characteristic asymmetric rounding with more intense material removal on the flank face. The evaluated values of $l_{\gamma}$ and $l_{\alpha}$ as well as their trend behaviour with increasing cutting length are comparable for all tested tool geometries with only slight differences with respect to the tested combinations of rake and clearance angles. This observation suggests that in machining $\Phi=0^{\circ}$, the wear-related change of R2 is mainly influenced by the fibre orientation itself. After a cutting length of $l_{c u l}=35 \mathrm{~m}, l_{\alpha}$ is roughly about two times longer than $l_{\gamma}$.

R3: As shown in Fig. 7, all tested tool geometries for $\Phi=0^{\circ}$ are characterised by a continuous reduction of the clearance angle due to a non-uniform material removal in $\mathrm{R} 3$ as shown by the corresponding cutting edge profiles. The wear-related trend of $\alpha^{*}$ is mainly influenced by the initial clearance angle but not the initial rake angle. Furthermore, the largest clearance angle in the new state of the cutting tool remains the largest also with increasing tool wear and vice versa. Although the absolute values of $\alpha^{*}$ are different, the relative reductions of $\alpha$ for a cutting length of $l_{c u t}=35 \mathrm{~m}$ are comparable for all tested tool geometries. Accordingly, initial clearance angles of $\alpha=7^{\circ}$, $\alpha=14^{\circ}$, and $\alpha=21^{\circ}$ decrease to $\alpha^{*} \approx 4^{\circ}(-42 \%), \alpha^{*} \approx 9^{\circ}$ $(-36 \%)$, and $\alpha^{*} \approx 12^{\circ}(-41 \%)$.

While the clearance angle is reduced because of wear, Figs. 7 and 8 reveal that the bouncing back height and the process forces, in particular the thrust force, increase clearly. Starting with a range of $2.4 \mu \mathrm{m}<b_{c}<6.5 \mu \mathrm{m}$ at $l_{\text {cut }}=5$ $\mathrm{m}$, the bouncing back height increases to a range of $8 \mu \mathrm{m}<$ $b_{c}<15.9 \mu \mathrm{m}$ at $l_{c u t}=35 \mathrm{~m}$. The highest bouncing back height in machining $\Phi=0^{\circ}$ is found to be $b_{c}=15.9 \mu \mathrm{m}$ for tool geometry $\mathrm{E}(10 / 7)$ at $l_{c u t}=35 \mathrm{~m}$, which in combination with $\alpha^{*}=3.9^{\circ}$ results in the longest friction length of $l_{f r}=234 \mu \mathrm{m}$.

When increasing the rake angle from $\gamma=10^{\circ}$ to $\gamma=30^{\circ}$ while the initial clearance angle of $\alpha=7^{\circ}$ remains unchanged, the bouncing back height and the friction length decrease independently from the actual wear state. Accordingly, with maximum values of $l_{f_{i}}=196 \mu \mathrm{m}$ and $l_{f i}=166 \mu \mathrm{m}$ at $l_{c u t}=35 \mathrm{~m}$, the 
friction lengths of tool geometries $\mathrm{J}\left(20 / 7^{\circ}\right)$ and $\mathrm{N}(30 / 7)$ are clearly shorter than for tool geometry E (10/7).

When increasing the clearance angle from $\alpha=7^{\circ}$ to $\alpha=21^{\circ}$ while the initial rake angle of $\gamma=10^{\circ}$ remains unchanged, the bouncing back height and the friction length decrease even more. With maximum values of $l_{f i}=74 \mu \mathrm{m}$ and $l_{f i}=43 \mu \mathrm{m}$ at $l_{\text {cut }}=35 \mathrm{~m}$, the friction length of tool geometries $\mathrm{H}(10 / 14)$ and I (10/21) are about $68 \%$ and $82 \%$ shorter than for tool geometry E (10/7). This strong reduction of friction length with increasing initial clearance angle is explained by the fact that cutting inserts with a larger initial clearance angle generally show a smaller bouncing back height. According to (2), a large clearance angle and a small bouncing back height result in a short friction length. The remaining tool geometries $\mathrm{L}(20$ / $14)$, $M(20 / 21)$, and $O(30 / 14)$ are characterised by the superposition of the effects mentioned above.

According to Fig. 8, especially the trend of the thrust force shows a similar dependence on the initial tool geometry as found for the bouncing back height. Although the thrust force increases independently on the tested combination of rake and clearance angles, it is shown that the wear-related increase of the thrust force is higher, the smaller the initial rake and clearance angles of the cutting tool are. In order to understand the revealed interrelations between the tool angles, the bouncing back height, and the resulting thrust force, the mechanics of material compression and the therefore resulting elastic spring back have to be considered. Furthermore, these interrelations have to be discussed under consideration of the operative part of the cutting edge, which continuously changes due to wear. As explained in Section 4.1, the spring back phenomenon in R3 is based on the material's response to its compression in $\mathrm{R} 2$ during the machining operation. The level of material compression is influenced by the shape and size of R2 and the acting process forces, which in combination define how many fibres can dive underneath the cutting edge. Due to the increasing bluntness of the cutting edge indicated by the larger values of $l_{\gamma}$ and $l_{\alpha}$, the material compression in R2 is intensified with advancing cutting length and hence continuously more fibres are pressed under the cutting edge during the machining operation. In consequence, the material's spring back potential increases as confirmed by means of the measured bouncing back heights in Fig. 7. A larger bouncing back height means in turn that the contact area at the flank face and thus R3 becomes larger resulting in higher force components due to friction. Due to the orientation of the flank face, these additional force components are mainly oriented in feed direction and hence cause increasing thrust forces. Simultaneously, this prioritisation of thrust force components is even intensified with progressive wear due to the decreasing clearance angle. Finally, these higher thrust forces intensify the material compression in $\mathrm{R} 2$ and therefore, in combination with the changing shape of $\mathrm{R} 2$, are responsible for the following wear changes of the cutting edge.

\subsection{Results: Interval II $\left(15^{\circ}<\Phi<75^{\circ}\right)$}

Representative for interval II, the wear-related change of the tools active micro-geometry is analysed in terms of the two fibre cutting angles $\Phi=30^{\circ}$ and $\Phi=60^{\circ}$ for a total cutting length of $l_{\text {cut }}=35 \mathrm{~m}$. While the wear trends of the five wear parameters $\left(l_{\alpha}, l_{\gamma}, \gamma^{*}, \alpha^{*}, b_{c}\right)$ and the friction length $l_{f r}$ are shown in Figs. 9 and 10 for $\Phi=30^{\circ}$ and $\Phi=60^{\circ}$, respectively, the corresponding cutting and thrust forces are revealed in Fig. 11.

R1: For both tested fibre cutting angles in interval II, the cutting edge profiles in Figs. 9 and 10 show no appreciable tool wear in R1. Accordingly, no wear-related changes are identified for the parameter $\gamma^{*}$, which means that the initial rake angle persists $\left(\gamma^{*}=\gamma\right)$ during the entire cutting length of $l_{\text {cut }}=35 \mathrm{~m}$. Consequently, no wear dependence in R1 on the initial set of rake and clearance angles is found. This clearly lower wear tendency in R1 compared to $\Phi=0^{\circ}$ is explained by the irregular tool load during the machining process due to different chip formation mechanisms. As explained in Section 4.2, the initial fibre separation and the subsequent secondary fibre fractures exclusively take place in R2, which in consequence is heavily loaded by the associated forces. In contrast, R1 is only faced with the already cut fibre ends that are pressed upwards along the rake face while occurring interlaminar cracks allow for lateral shearing-off of adjacent fibre layers. According to Section 4.2, the associated contact forces and thus the resulting tool load in R1 are very low which explains the absence of rake wear.

R2: According to Figs. 9 and 10, R2 shows intense mechanical wear resulting in an increasing bluntness of the cutting tool which is indicated by continuously increasing values of $l_{\gamma}$ and $l_{\alpha}$. As explained above, this strong tool wear in R2 is due to high contact forces in consequence of the initial fibre separation occurring in R2 and the following subsequent secondary fibre fractures along the tool shape between points B and C. Analogous to the results in interval I, the parameter $l_{\alpha}$ always increases clearly faster than $l_{\gamma}$ which means that the cutting tools are characterised by an increasing asymmetric cutting edge rounding with more intense material removal on the flank face. In numbers, the maximum values of $l_{\gamma}$ and $l_{\alpha}$ for $\Phi=30^{\circ}$ after a cutting length of $l_{\text {cut }}=35 \mathrm{~m}$ lie between $18 \mu \mathrm{m} \leq$ $l_{\gamma} \leq 21 \mu \mathrm{m}$ and $39 \mu \mathrm{m} \leq l_{\alpha} \leq 45 \mu \mathrm{m}$ depending on the tested tool geometry. Analogous for $\Phi=60^{\circ}$, the respective ranges are $22 \mu \mathrm{m} \leq l_{\gamma} \leq 24 \mu \mathrm{m}$ and $40 \mu \mathrm{m} \leq l_{\alpha} \leq 52 \mu \mathrm{m}$. These rather small value ranges indicate that for both fibre cutting angles, the wear-related change of R2 is mainly influenced by the fibre orientation and not by the initial set of rake and clearance angles.

In direct comparison, it can be noted that the value of $l_{\alpha}$ is generally larger for $\Phi=60^{\circ}$ than for $\Phi=30^{\circ}$, while the value of $l_{\gamma}$ is mostly comparable for both fibre cutting angles. In 


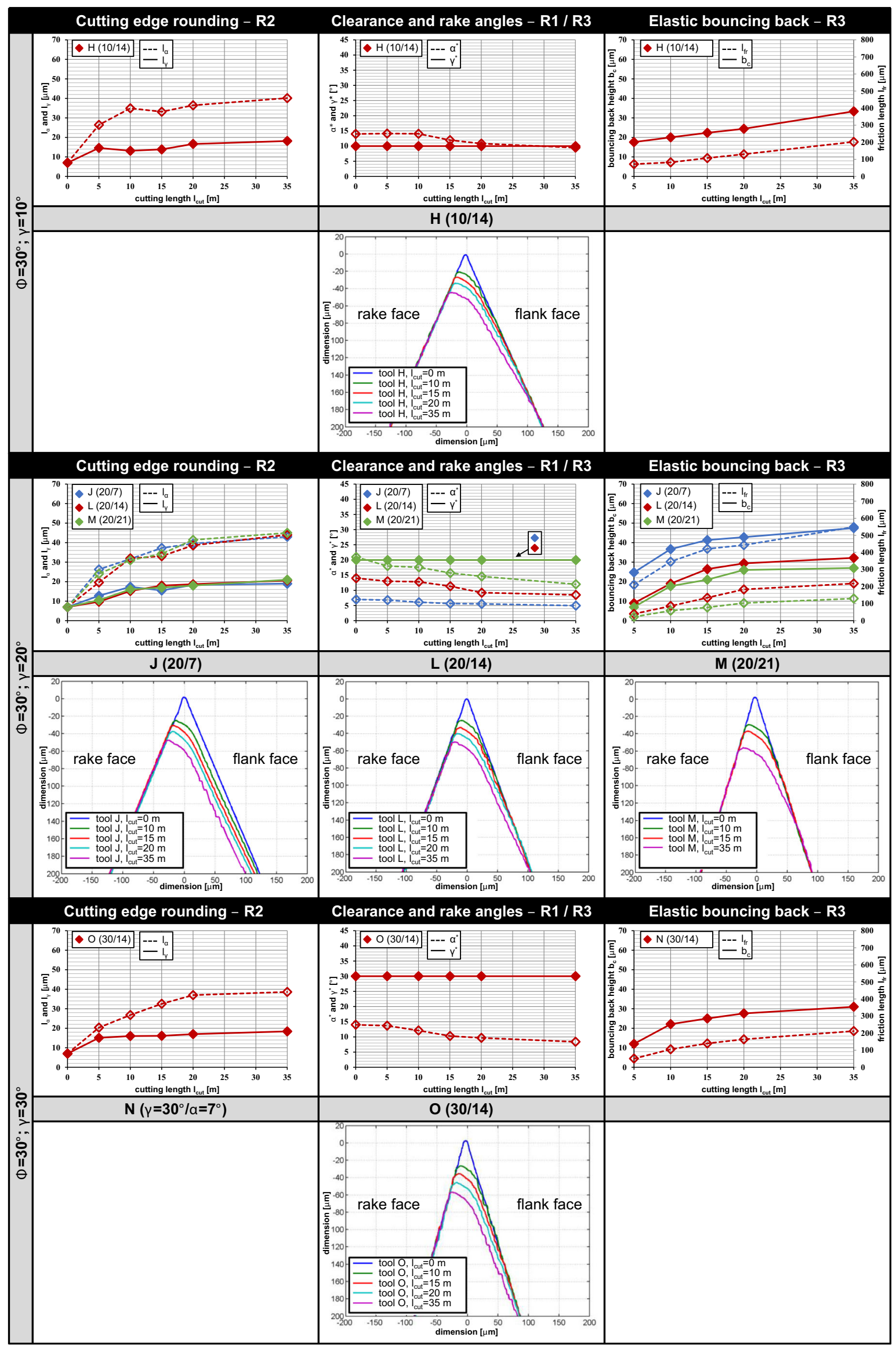


4 Fig. 9 Wear evaluation for UD CFRP material with $\Phi=30^{\circ}$; trends of the wear parameters $\left(l_{\alpha}, l_{\gamma}, \gamma^{*}, \alpha^{*}, b_{c}\right)$; and the friction length $l_{f r}$ as function of the cutting length for all tested sets of rake and clearance angles $\left(v_{c}=90\right.$ $\mathrm{m} / \mathrm{min}, f=0.03 \mathrm{~mm} / \mathrm{rev}$ )

consequence, machining $\Phi=30^{\circ}$ results in a more pronounced asymmetric cutting edge rounding as confirmed by the corresponding cutting edge profiles shown in Figs. 9 and 10. By referring to the schematic illustration in Fig. 6b, this observation can be explained by the first tool/fibre contact point $T$ and its importance for the tool wear behaviour in R2. According to Section 4.2, the initial fibre separation occurs close to point $\mathrm{T}$. Subsequently the whole contact region between points $\mathrm{T}$ and $\mathrm{C}$ in $\mathrm{R} 2$, the so-called rubbing area, is faced by repetitive micro bending deflections resulting in strong mechanical abrasion. Assuming a new cutting edge $\left(l_{\gamma}=l_{\alpha}\right)$, the contact point $\mathrm{T}$ is closer to point $\mathrm{B}$ the larger the fibre cutting angle, which means that the percentage contribution of the rubbing area to the entire contact length of R2 increases with increasing fibre cutting angle. Since especially the rubbing area is affected by mechanical wear due to the secondary fibre cracks, a larger rubbing area means that tool wear is more uniformly distributed over R2 than for a small rubbing area. Consequently, machining $\Phi=30^{\circ}$ is associated with a stronger one-sided degeneration of the cutting edge resulting in smaller values for $l_{\gamma}$.

R3: According to Figs. 9 and 10, progressive tool wear in R3 results in a continuously decreasing clearance angle while simultaneously the bouncing back height and thus in combination the friction length increases. Furthermore, Fig. 11 reveals that the process forces, in particular the thrust forces, rise with increasing cutting length. The interrelations of these parameters have already been discussed in detail in Section 5.1 and therefore are not repeated here. Comparable to the findings in interval I, the wear-related trend of $\alpha^{*}$ mainly depends on the initial clearance angle, while the influence of the initial rake angle is small. Again, the largest clearance angle in the new state of the cutting tool remains the largest also with increasing tool wear and vice versa.

For $\Phi=30^{\circ}$, the bouncing back height starts with a range of $7 \mu \mathrm{m}<b_{c}<24.5 \mu \mathrm{m}$ at $l_{c u t}=5 \mathrm{~m}$ and subsequently increases clearly to a range of $27 \mu \mathrm{m}<b_{c}<47.5 \mu \mathrm{m}$ after a cutting length of $l_{c u t}=35 \mathrm{~m}$. With $b_{c}=47.5 \mu \mathrm{m}$, the highest bouncing back height is found for tool geometry $\mathrm{J}(20 / 7)$ at $l_{\text {cut }}=35 \mathrm{~m}$, which in combination with $\alpha^{*}=5^{\circ}$ results in the longest friction length of $l_{f i}=549 \mu \mathrm{m}$. When increasing the clearance angle from $\alpha=7^{\circ}$ to $\alpha=14^{\circ}$ and $\alpha=21^{\circ}$ while the initial rake angle of $\gamma=20^{\circ}$ remains unchanged, the bouncing back height and the friction length are clearly reduced. With maximum values of $l_{f r}=218 \mu \mathrm{m}$ and $l_{f i}=130 \mu \mathrm{m}$ at $l_{c u t}=35 \mathrm{~m}$, the friction length of the tool geometries L (20/14) and M (20/14) are about 60\% and $76 \%$ shorter than for the tool geometry J (20/7).
For $\Phi=60^{\circ}$, the bouncing back height starts with a range of $6.3 \mu \mathrm{m}<b_{c}<23 \mu \mathrm{m}$ at $l_{c u t}=5 \mathrm{~m}$ and subsequently increases clearly to a range of $17.6 \mu \mathrm{m}<b_{c}<46 \mu \mathrm{m}$ after a cutting length of $l_{c u t}=35 \mathrm{~m}$. With $b_{c}=46 \mu \mathrm{m}$, the highest bouncing back height is found for tool geometry $\mathrm{J}(20 / 7)$ at $l_{\text {cut }}=35 \mathrm{~m}$, which in combination with $\alpha^{*}=3.4^{\circ}$ results in the longest friction length of $l_{f i}=776 \mu \mathrm{m}$. Analogous to machining $\Phi=30^{\circ}$, the bouncing back height and the friction length decrease if the initial clearance angle is increased while the initial rake angle remains unchanged. With maximum values of $l_{f i}=206 \mu \mathrm{m}$ and $l_{f r}=60 \mu \mathrm{m}$ at $l_{c u t}=35 \mathrm{~m}$, the friction length of tool geometries L (20/14) and $\mathrm{M}(20 / 21)$ are about $74 \%$ and $92 \%$ shorter than for tool geometry J (20/7).

As explained above, the rubbing area and thus the theoretical material compression in R2 are larger, the larger the fibre cutting angle is due to the location of the first tool/fibre contact point $\mathrm{T}$. Consequently, the level of material compression and thus the resulting thrust force and bouncing back height are expected to be higher for $\Phi=60^{\circ}$ than for $\Phi=30^{\circ}$. Instead, Fig. 11 reveals that the thrust forces, in particular in the heavily worn state of the cutting tool, are generally higher for $\Phi=30^{\circ}$ than for $\Phi=60^{\circ}$. Furthermore, the difference in thrust force depends on the initial tool geometry and is larger, the larger the initial clearance angle of the cutting insert is. A look at the corresponding bouncing back heights in Figs. 9 and 10 shows a similar situation, where the results of $b_{c}$ are comparable for tools with an initial clearance angle of $\alpha=7^{\circ}$, but not for those with $\alpha=14^{\circ}$ and $\alpha=21^{\circ}$. In order to explain this observation, the CFRP material in the contact region has to be analysed. For this purpose, representative micrographs from Henerichs [41] are used, who performed orthogonal machining experiments with identical tool geometries, process parameters, and material properties. These micrographs are summarised in Fig. 12 , showing the CFRP material parallel to the cutting velocity direction for the tool geometries identical to J (20/7), L (20/ 14), and $\mathrm{M}(20 / 21)$ at $\Phi=30^{\circ}$ and $\Phi=60^{\circ}$ after a cutting length of $l_{\text {cul }}=10 \mathrm{~m}$. The feed rate and the measured bouncing back heights are highlighted as colour bars in Fig. 12 in red and blue, respectively.

For tool geometry J (20/7), the micrographs in Fig. 12 show sporadic fibre cracks in the subsurface for both fibre cutting angles. Most of the fibre cracks are limited to a little number of adjacent fibres, whereas continuous cracks through several fibre layers are the exception. Although the micrographs show slightly more cracks for $\Phi=60^{\circ}$, no fibre crack deeper than the superposition of $f$ and $b_{c}$ is identified. This means that for both fibre cutting angles, the pre-damaged CFRP material is completely removed during the subsequent spindle rotation, and the bounced back CFRP material is not influenced by material weakening due to material damages of the previous spindle rotation. A comparable level of subsurface damage indicates comparable spring back behaviour and similar thrust forces. This is experimentally confirmed in Figs. 9, 10, and 11. 


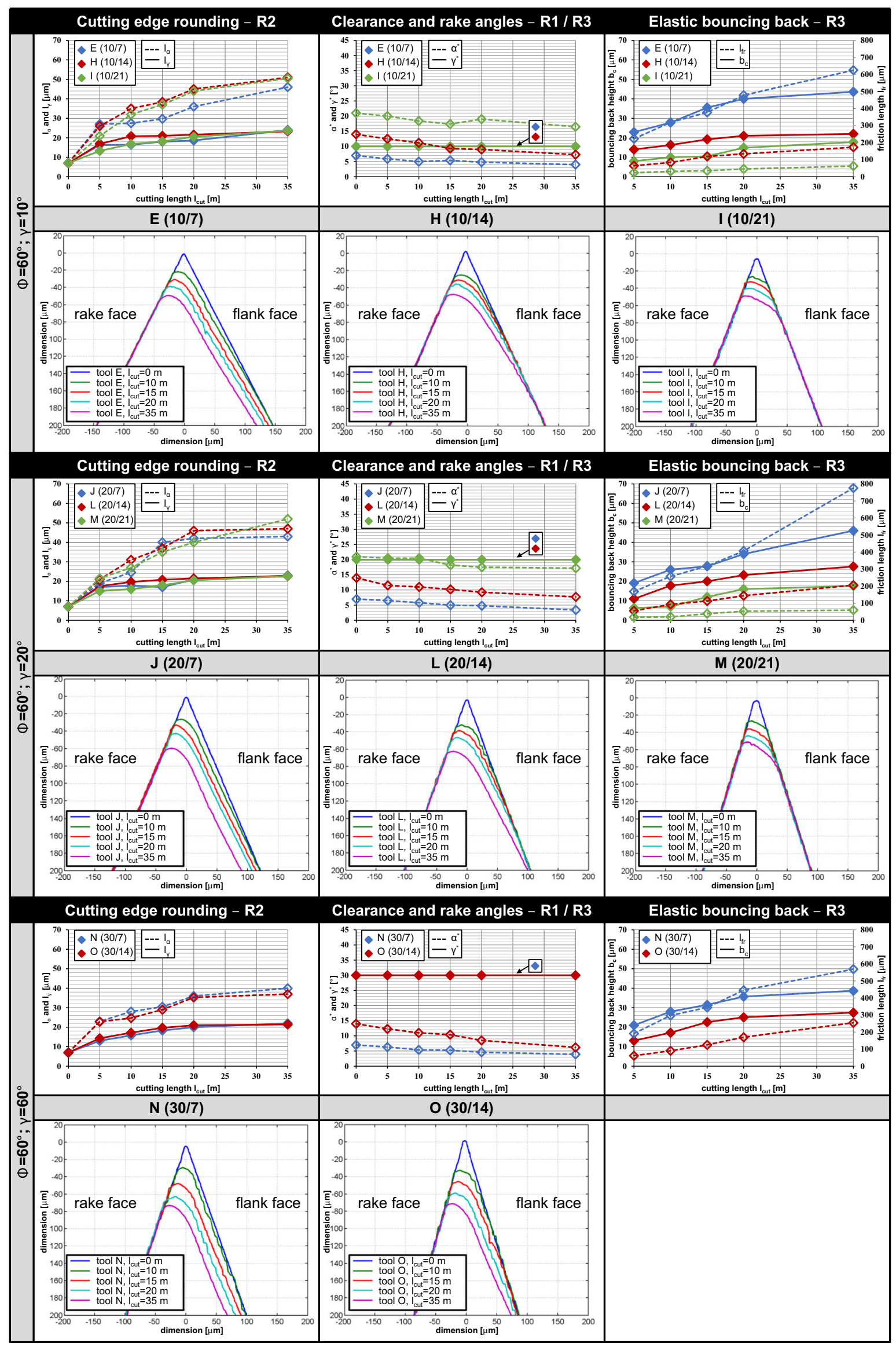


Fig. 10 Wear evaluation for UD CFRP material with $\Phi=60^{\circ}$; trends of the wear parameters $\left(l_{\alpha}, l_{\gamma}, \gamma^{*}, \alpha^{*}, b_{c}\right)$; and the friction length $l_{f r}$ as function of the cutting length for all tested sets of rake and clearance angles $\left(v_{c}=90 \mathrm{~m} / \mathrm{min}, f=0.03 \mathrm{~mm} / \mathrm{rev}\right)$

According to Fig. 12, the level of subsurface damage increases for both fibre cutting angles if a cutting insert with a larger initial clearance angle is used. In this context, significant differences are identified for $\Phi=30^{\circ}$ and $\Phi=60^{\circ}$. For $\Phi=30^{\circ}$, increasing the initial clearance angle results in slightly more subsurface fibre cracks, which, however, are still mainly limited to a little number of adjacent fibre layers close to the surface area. These fibre cracks are still not exceeding the superposition of $f$ and $b_{c}$, which means that the pre-damaged material is completely removed during the following spindle rotation. In contrast, increasing the initial clearance angle for $\Phi=60^{\circ}$ results in large continuous cracks that run periodically across the adjacent fibres. Since these fibre cracks are identified up to a depth of 110 $\mu \mathrm{m}$, they repetitively exceed the superposition of $f$ and $b_{c}$. Consequently, the cracks cannot be completely removed by the subsequent spindle rotation and instead, most likely propagate during consecutive spindle rotations, which means that the spring back potential of the composite material in the current spindle rotation is influenced by the subsurface damages generated in previous spindle rotations. It is assumed that a high level of subsurface damage leads to an overall stress relaxation in the CFRP material, which reduces the spring back potential after passing point $\mathrm{C}$ and thus the resulting bouncing back height. This statement corresponds to the experimental findings shown in Figs. 9, 10, and 11. For tool L (20/14), the bouncing back height is about $14.3 \%$ and the thrust force about $26.3 \%$ lower for $\Phi=60^{\circ}$ than for $\Phi=30^{\circ}$. For tool M (20/21), the bouncing back height is about $34.8 \%$ and the thrust force about $49.5 \%$ lower for $\Phi=60^{\circ}$ than for $\Phi=30^{\circ}$.

\subsection{Results: Interval III $\left(75^{\circ}<\Phi \leq 90^{\circ}\right)$}

Representative for interval III, the wear-related change of the tools active micro-geometry is analysed in terms of the fibre cutting angle $\Phi=90^{\circ}$ for a total cutting length of $l_{c u t}=35 \mathrm{~m}$. While the wear-related trends of the five wear parameters $\left(l_{\alpha}\right.$, $l_{\gamma}, \gamma^{*}, \alpha^{*}, b_{c}$ ) and the friction length $l_{f r}$ are shown in Figs. 13 and 14 reveals the corresponding cutting and thrust forces analogous to the previous intervals.

R1: According to the cutting edge profiles presented in Fig. 13, no appreciable tool wear is identified in R1 for all tested tool geometries, and hence the initial rake angles persist during the entire machining operation $\left(\gamma=\gamma^{*}\right)$. Consequently, no wear dependence in $\mathrm{R} 1$ on the initial set of rake and clearance angle is found.

Comparable to interval II, the absence of heavy wear effects in R1 is explained by the chip formation mechanism and the resulting tool load on the rake face. As explained in detail in Section 4.3 , the rake face of the cutting tool is mainly faced by the already cut fibre ends for $\Phi=90^{\circ}$. Since these free fibre ends are separated from the remaining CFRP material, the tool motion allows for lateral shearing-off of adjacent fibre layers where only the comparable low shear strength of the matrix material has to be exceeded. In combination with simultaneously

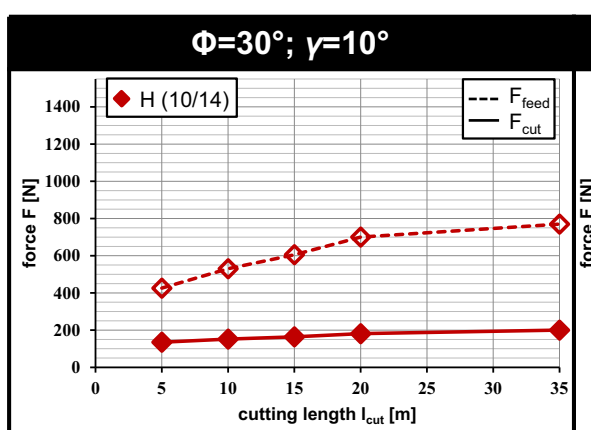

$\Phi=60^{\circ} ; y=10^{\circ}$

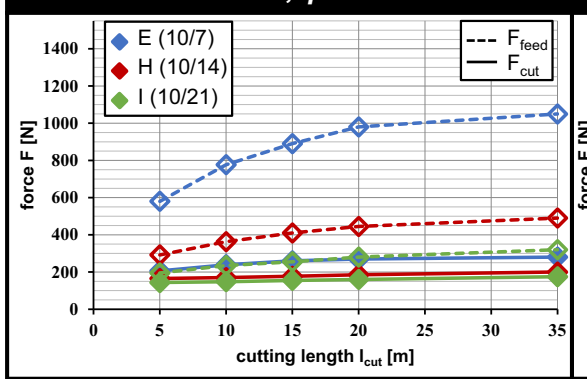

$\Phi=30^{\circ} ; y=20^{\circ}$

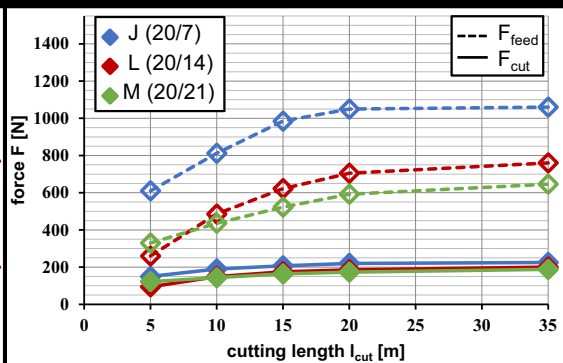

$\Phi=60^{\circ} ; y=20^{\circ}$

\section{$\Phi=30^{\circ} ; y=30^{\circ}$}

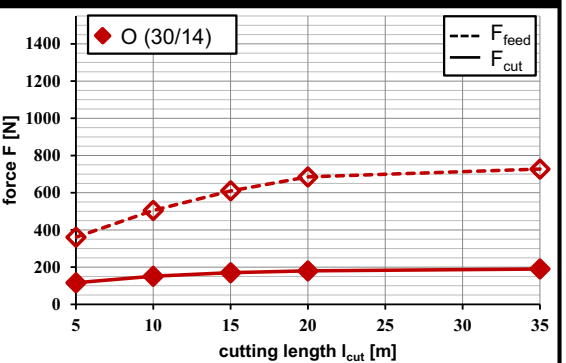

$\Phi=60^{\circ} ; y=30^{\circ}$

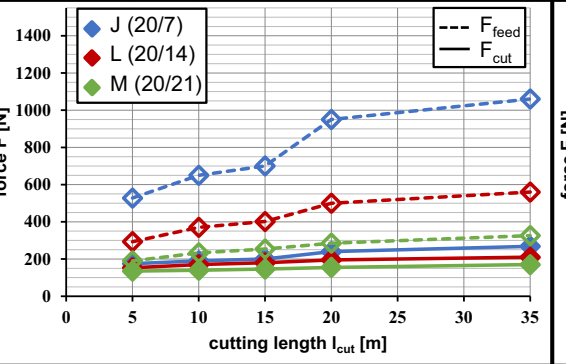

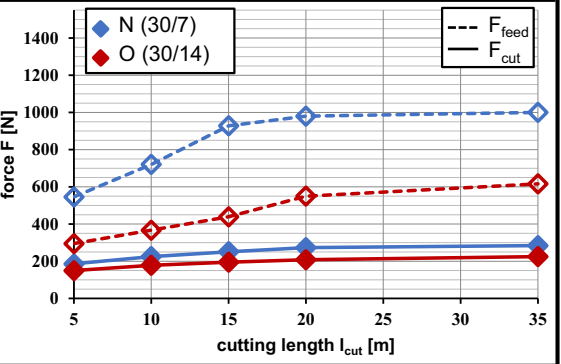

Fig. 11 Cutting and thrust forces in machining UD CFRP material with $\Phi=30^{\circ}$ and $\Phi=60^{\circ}\left(v_{c}=90 \mathrm{~m} / \mathrm{min}, f=0.03 \mathrm{~mm} / \mathrm{rev}\right)$ 


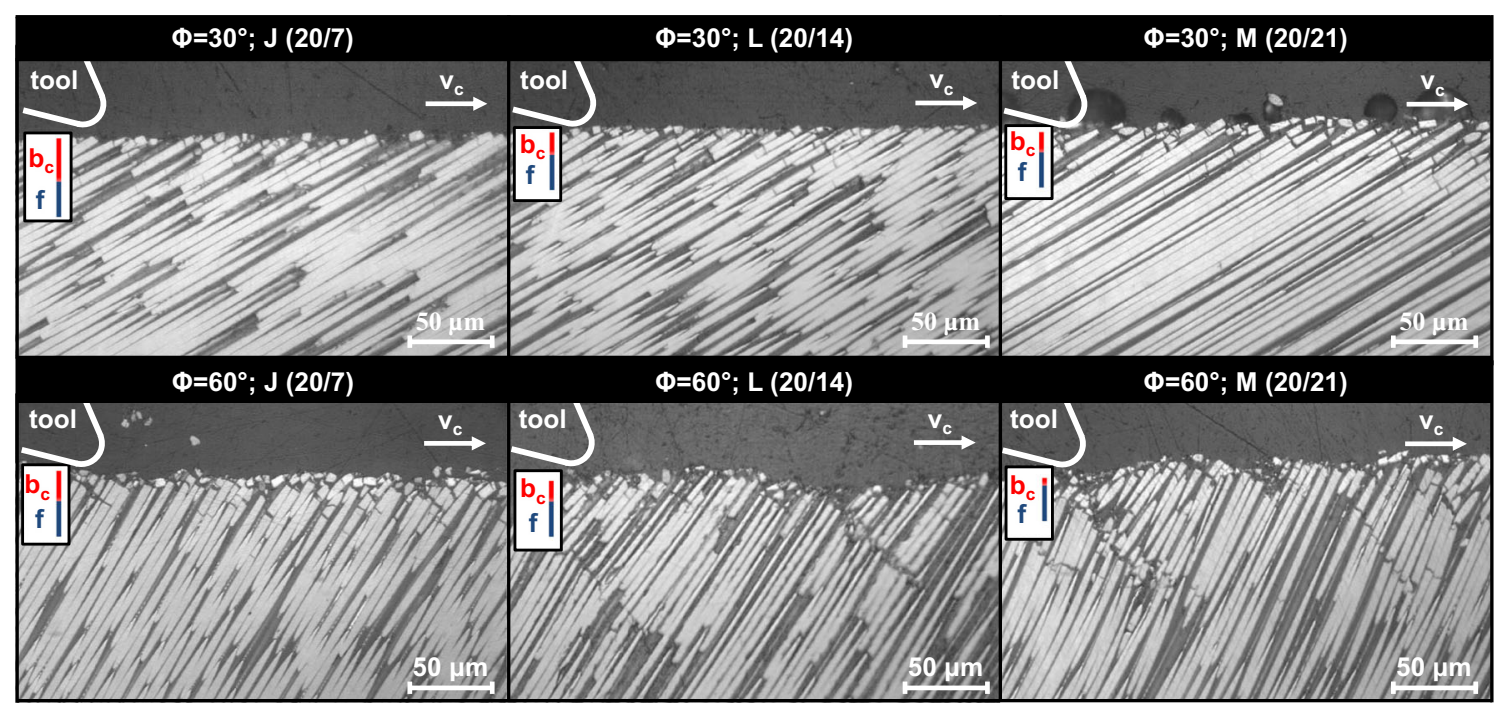

Fig. 12 Representative micrographs parallel to the cutting velocity direction for tool geometries with different initial clearance angles for fibre cutting angles of $\Phi=30^{\circ}$ and $\Phi=60^{\circ} ; l_{c u l}=10 \mathrm{~m}, v_{c}=90 \mathrm{~m} / \mathrm{min}, f=0.03 \mu \mathrm{m} / \mathrm{rev}[41]$

occurring interlaminar fibre cracks in front of the cutting edge, the resulting tool load in R1 and thus the corresponding wear potential is small.

R2: Comparable to the previous intervals, Fig. 13 reveals that machining $\Phi=90^{\circ}$ is characterised by an asymmetric cutting edge rounding, where the parameter $l_{\alpha}$ always increases clearly faster than $l_{\gamma}$. The maximum values of $l_{\gamma}$ and $l_{\alpha}$ after a cutting length of $l_{c u t}=35 \mathrm{~m}$ lie between $21 \mu \mathrm{m} \leq l_{\gamma} \leq 29 \mu \mathrm{m}$ and $40 \mu \mathrm{m} \leq l_{\alpha} \leq 48 \mu \mathrm{m}$ depending on the tested tool geometry. According to Fig. 13, the wear-related change of R2 is mainly influenced by the fibre orientation and not by the initial set of rake and clearance angles. In direct comparison with interval II, it is observed that the value of $l_{\alpha}$ is generally larger for $\Phi=90^{\circ}$ than for $\Phi=30^{\circ}$ and $\Phi=60^{\circ}$, while the value of $l_{\gamma}$ is mostly comparable for all fibre cutting angles. This is explained by the corresponding rubbing area which is introduced in Section 5.2. Moreover, the first tool/fibre contact point $\mathrm{T}$ is identical to point B as shown in the schematic illustration in Fig. 6c. As a result, the rubbing area extends to the entire contact length of R2, which, in accordance with the explanations in Section 5.2, reduces a one-sided degeneration of the cutting edge. Consequently, the asymmetric cutting edge rounding in $\mathrm{R} 2$ is less pronounced for $\Phi=90^{\circ}$ than for $\Phi=30^{\circ}$ and $\Phi=60^{\circ}$.

R3: According to Fig. 13, tool geometries with an initial clearance angle of $\alpha=7^{\circ}$ or $\alpha=14^{\circ}$ are characterised by a continuously decreasing value of $\alpha^{*}$, while the bouncing back height, the friction length, and the process forces increase. For these tool geometries, the wear-related trend of $\alpha^{*}$ is driven by the initial clearance angle, while the influence of the initial rake angle is negligible. Analogous to the findings in other intervals, the largest clearance angle in the new state of the cutting tool remains the largest also with increasing tool wear and vice versa. In contrast to tool geometries with initial clearance angles of $\alpha=7^{\circ}$ and $\alpha=14^{\circ}$, those with $\alpha=21^{\circ}$ show nearly no wear-related changes of the flank face, and hence the clearance angle is nearly constant during the machining operation $\left(\alpha=\alpha^{*}\right)$. This phenomenon is unique in this study and only found for tool geometries I (10/21) and M (20/21) in machining $\Phi=90^{\circ}$. The absence of wear-related changes on the flank face means that R3 is very small and the mechanical abrasion within R3 is nearly negligible.

In order to explain the above observations, the corresponding process forces in Fig. 14 have to be taken into account. In this context, it can be seen that the tools I (10/21) and M (20/ 21) are characterised by very low thrust forces if compared to other tool geometries or fibre cutting angles. With values around $200 \mathrm{~N}$ after a cutting length of $l_{c u t}=35 \mathrm{~m}$, these tools show the overall lowest thrust forces evaluated in this study. Based on the interrelations of the thrust force, the material compression, and the resulting spring back explained in Section 5.1, these low thrust forces are associated with small bouncing back heights around $b_{c}=8 \mu \mathrm{m}$ as shown in Fig. 13. With $b_{c}=21 \mu \mathrm{m}$, the overall highest bouncing back height in machining $\Phi=90^{\circ}$ is found for tool geometry E (10/7) at $l$ ${ }_{c u t}=35 \mathrm{~m}$, which in combination with a worn clearance angle of $\alpha^{*}=3.5^{\circ}$ results in the longest friction length of $l_{f r}=344 \mu \mathrm{m}$. When increasing the clearance angle from $\alpha=7^{\circ}$ to $\alpha=14^{\circ}$ and $\alpha=21^{\circ}$ while the initial rake angle of $\gamma=10^{\circ}$ remains unchanged, the bouncing back height and the friction length decrease significantly. With maximum values of $l_{f r}=89.5 \mu \mathrm{m}$

Fig. 13 Wear evaluation for UD CFRP material with $\Phi=90^{\circ}$; trends of the wear parameters $\left(l_{\alpha}, l_{\gamma}, \gamma^{*}, \alpha^{*}, b_{c}\right)$; and the friction length $l_{f r}$ as function of the cutting length for all tested sets of rake and clearance angles $\left(v_{c}=90\right.$ $\mathrm{m} / \mathrm{min}, f=0.03 \mathrm{~mm} / \mathrm{rev}$ ) 


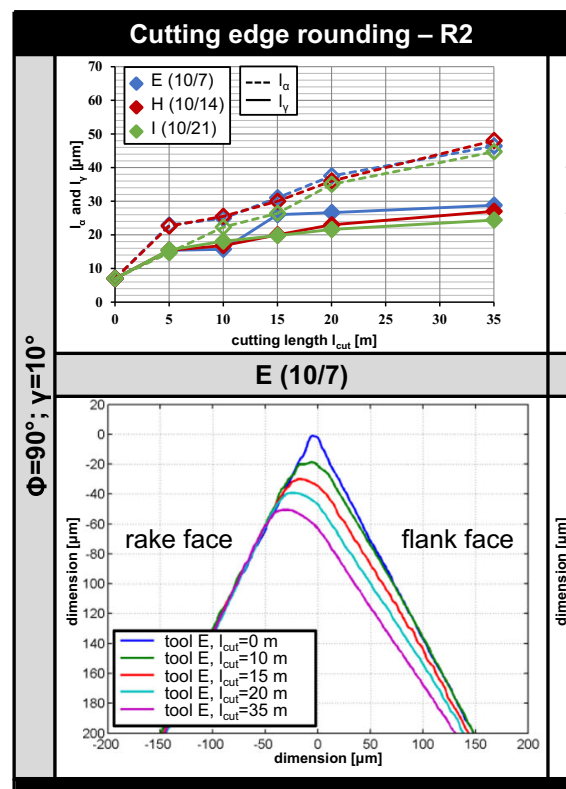

Clearance and rake angles - R1 / R3

Elastic bouncing back - R3

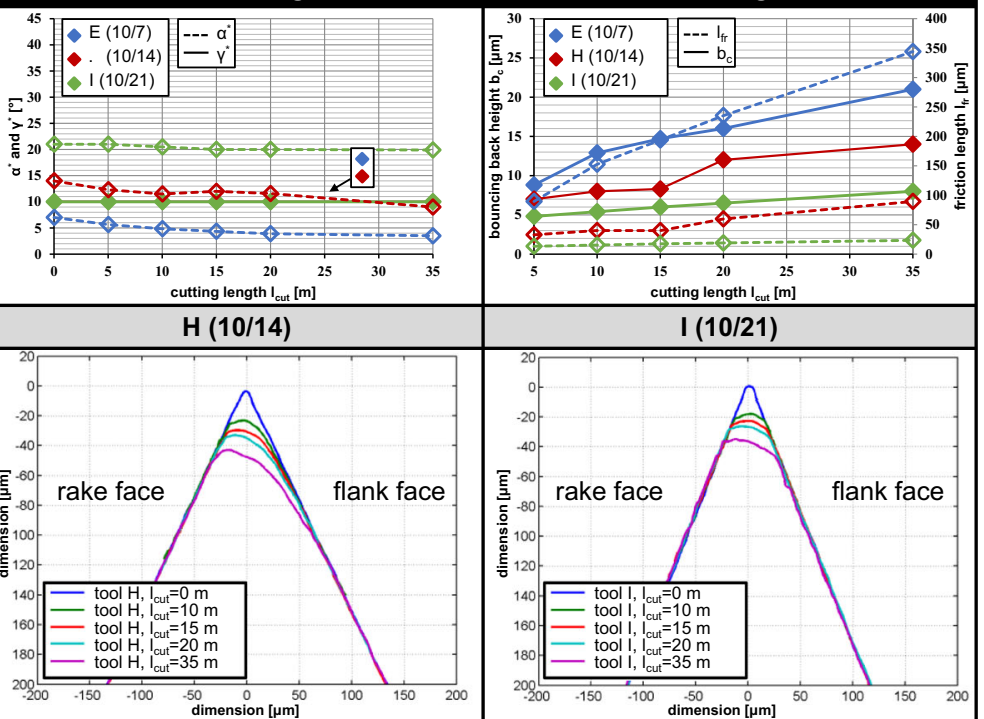

\section{Cutting edge rounding $-\mathbf{R} 2$}

Clearance and rake angles - R1 / R3
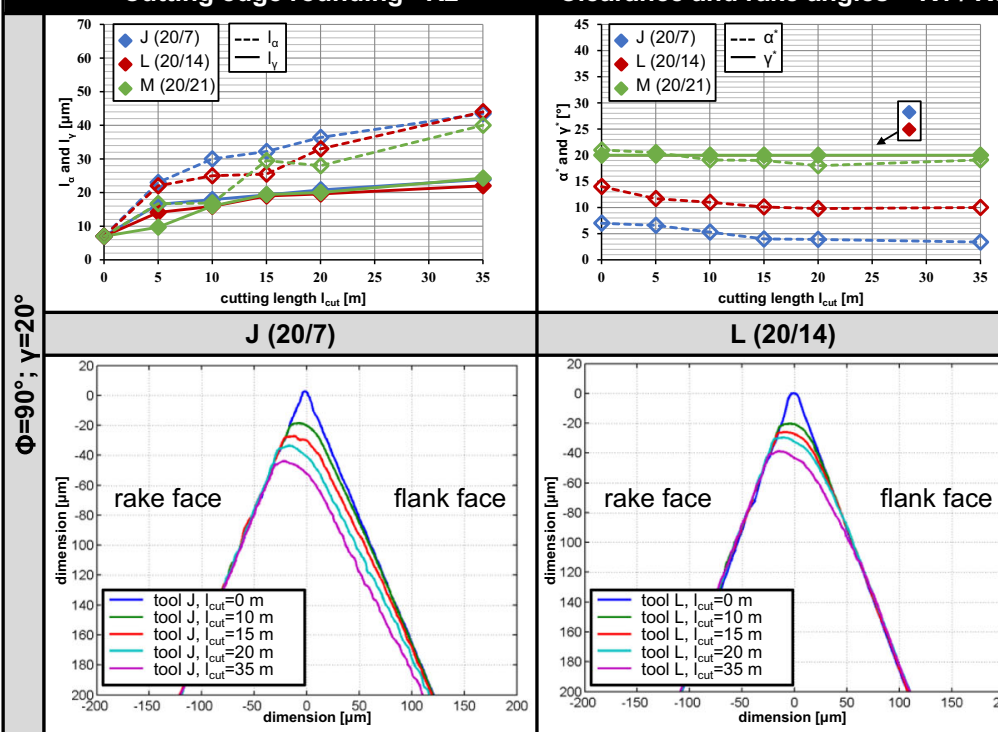

Elastic bouncing back - R3

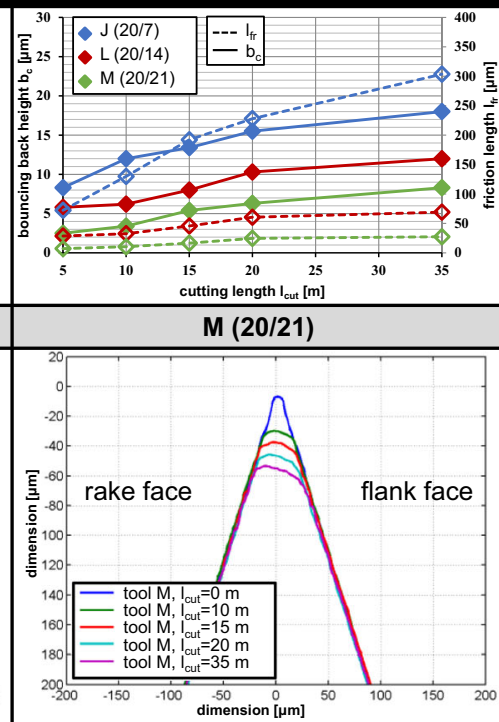

\section{Cutting edge rounding - R2}

\section{Clearance and rake angles - R1 / R3}
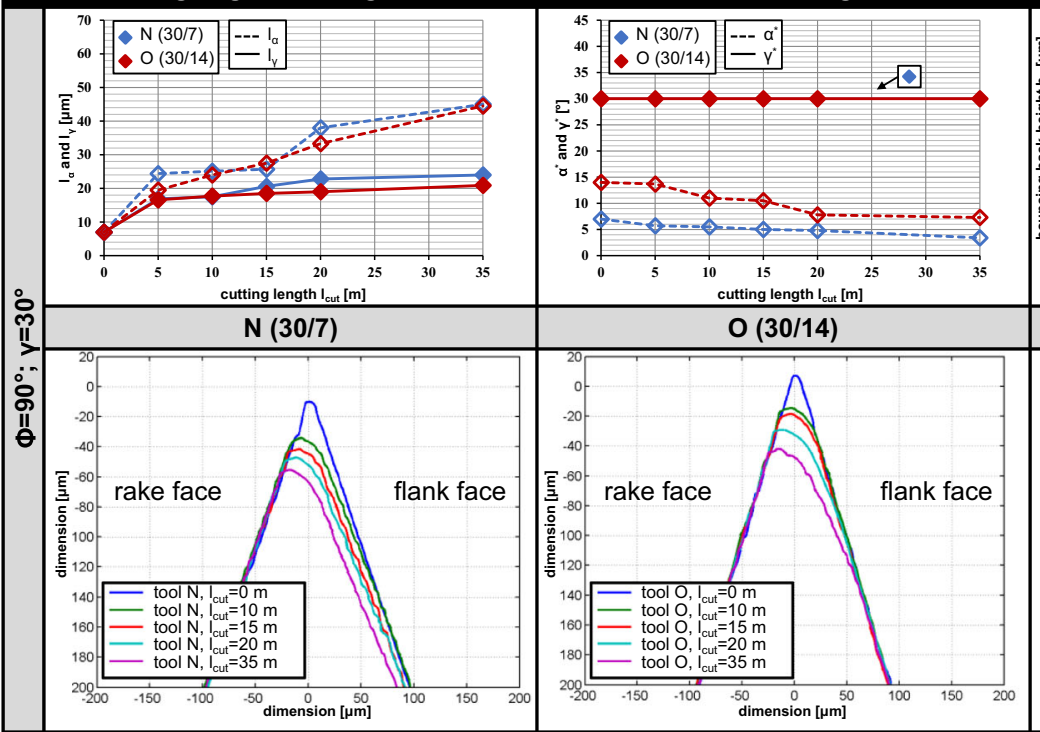

Elastic bouncing back - R3

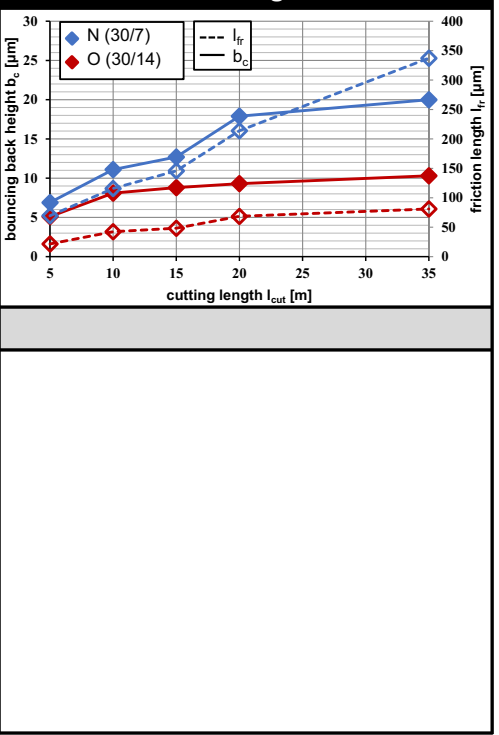


and $l_{f r}=23.5 \mu \mathrm{m}$ at $l_{c u l}=35 \mathrm{~m}$, the friction length of tool geometries $\mathrm{H}(10 / 14)$ and $\mathrm{I}(10 / 21)$ are about $74 \%$ and $93 \%$ shorter than for tool geometry E (10/7). When increasing the rake angle from $\gamma=10^{\circ}$ to $\gamma=20^{\circ}$ and $\gamma=30^{\circ}$ while the initial clearance angle of $\alpha=7^{\circ}$ remains unchanged, the bouncing back height as well as the friction length do not show consistent trends. Instead, both values slightly decrease if the initial rake angle is changed from $\gamma=10^{\circ}$ to $\gamma=20^{\circ}$, however, subsequently increase again if the initial rake angle is increased to $\gamma=30^{\circ}$.

In direct comparison to $\Phi=30^{\circ}$ and $\Phi=60^{\circ}$, the bouncing back height in machining $\Phi=90^{\circ}$ is clearly smaller although the rubbing area and thus the theoretical material compression are the largest. In order to explain this discrepancy, the CFRP material in the contact region has to be analysed. For this purpose and analogous to Section 5.2, representative micrographs of Henerichs [41] are used which show the CFRP material parallel to the cutting velocity direction. Figure 15 shows the micrographs for the tool geometries J (20/7), L (20/14), and $\mathrm{M}(20 / 21)$ at $\Phi=90^{\circ}$ after a cutting length of $l$ cul $=10 \mathrm{~m}$, while the feed rate and the measured bouncing back heights are highlighted as colour bars in red and blue, respectively. As shown in Fig. 15, in machining $\Phi=90^{\circ}$, all tools are characterised by considerable subsurface damages in the CFRP material under the cutting edge. In this context, repetitive fibre cracks propagating through several fibre layers are identified up to a depth of $117 \mu \mathrm{m}$. Since the therefore predamaged CFRP material repetitively exceeds the superposition of $f$ and $b_{c}$, this means that these defects cannot be removed by the subsequent spindle rotation and, instead, propagate during consecutive spindle rotations. As explained in Section 5.2, these subsurface damages cause a stress relaxation in the CFRP material and therefore reduce the material's spring back potential. By comparing Figs. 12 and 15, the level of subsurface damage is much higher for $\Phi=90^{\circ}$ than for $\Phi=30^{\circ}$ and $\Phi=60^{\circ}$. Accordingly, the spring back potential for $\Phi=90^{\circ}$ is assumed to be clearly reduced which corresponds to the evaluated spring back data.

\subsection{Results: Wear rate}

In this section, the amount of removed tool material in terms of the two-dimensional wear rate $A_{w}$ defined in
Section 3.3 is presented. In this context, Fig. 16 shows the wear-related change of $A_{w}$ for all tested tool geometries and fibre cutting angles for a maximum cutting length of $l_{c u t}=35 \mathrm{~m}$. For the sake of clarity, these results are subdivided into rows and columns with respect to the fibre cutting angle and the initial rake angle, respectively. Whereas for $\Phi=30^{\circ}, \Phi=60^{\circ}$, and $\Phi=90^{\circ}$ the same scaling is used for the ordinate, a smaller scale is applied for $\Phi=0^{\circ}$ in order to take the overall lower level of mechanical wear into account. Based on the number of wear analysis steps, each trend line is described by five supporting points at $l$ ${ }_{c u t}=5 \mathrm{~m}, l_{\text {cut }}=10 \mathrm{~m}, l_{\text {cut }}=15 \mathrm{~m}, l_{\text {cut }}=20 \mathrm{~m}$, and $l_{\text {cut }}=35 \mathrm{~m}$.

Although the total amount of removed tool material strongly varies depending on the initial tool geometry and the fibre cutting angle, Fig. 16 indicates that in any case, the value of $A_{w}$ increases almost linearly with increasing cutting length. In this context, a linear increase of $A_{w}$ means that the removed tool material per metre cutting length and thus the corresponding wear rate is constant and not affected by progressive tool wear. However, the material loss because of wear is unequally distributed over the tool's contact region, which means that knowing the value of $A_{w}$ and its trends is not enough to reproduce the tool shape of a worn cutting edge. Furthermore, it has to be considered that the active micro-geometry and thus its contact length are getting larger with progressive wear as shown in Sections 5.1, 5.2, and 5.3. Therefore, a constant wear rate means that the same amount of removed tool material is distributed over an increasingly larger tool surface.

In machining $\Phi=0^{\circ}$, the amount of worn tool material for a cutting length of $l_{c u t}=35 \mathrm{~m}$ varies in a range between $A_{w}=976 \mu \mathrm{m}^{2}$ (tool E) and $A_{w}=617 \mu \mathrm{m}^{2}$ (tool O). Consequently, the initial tool geometry has an influence on the amount of removed tool material and thus the wear rate. According to Fig. 16, the value of $A_{w}$ after $l_{\text {cut }}=35 \mathrm{~m}$ is larger, the smaller the values of the initial clearance and rake angles of the cutting insert are. In this context, the wear analysis in Section 5.1 shows that tools with a small initial clearance angle are characterised by larger bouncing back heights and friction length which means that the wear-affected area on the flank face and thus the corresponding material loss are more intense if compared to tools with larger initial clearance angles. Furthermore, the

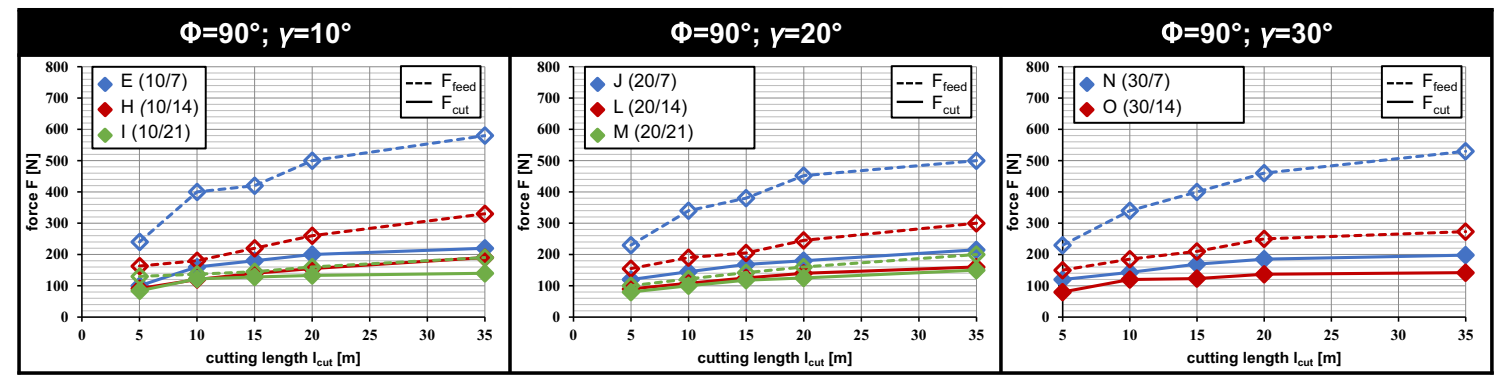

Fig. 14 Cutting and thrust forces in machining UD CFRP material with $\Phi=90^{\circ}\left(v_{c}=90 \mathrm{~m} / \mathrm{min}, f=0.03 \mathrm{~mm} / \mathrm{rev}\right)$ 


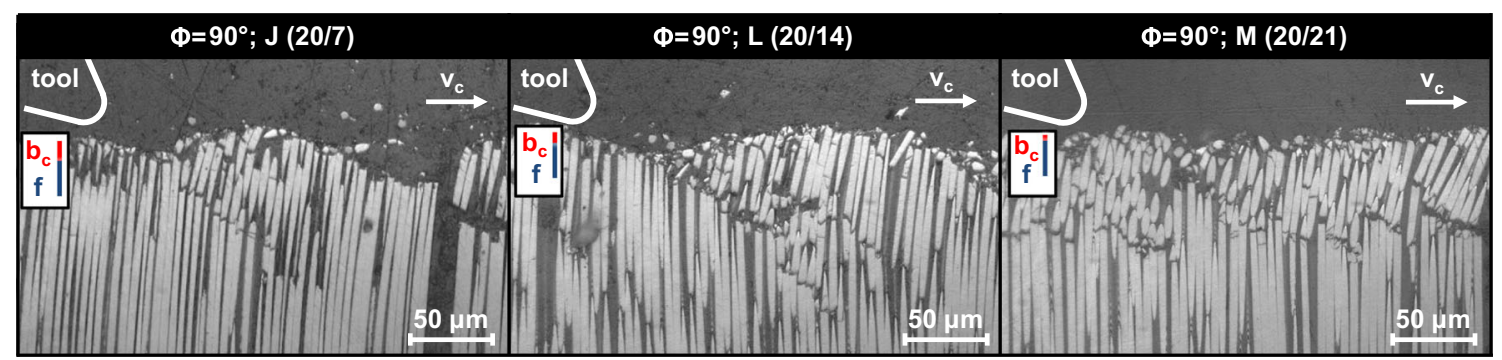

Fig. 15 Micrographs parallel to the cutting velocity direction for tool geometries with different initial clearance angles for a fibre cutting angle of $\Phi=90^{\circ}$; $l_{\text {cul }}=10 \mathrm{~m}, v_{c}=90 \mathrm{~m} / \mathrm{min}, f=0.03 \mu \mathrm{m} / \mathrm{rev}$ [41]

wear analysis reveals that tools with a small initial rake angle experience progressive tool wear in $\mathrm{R} 1$, which is measured as an increase of $A_{w}$. In contrast, tools with large initial rake angles do not show this wear on the rake face. The missing contribution of $\mathrm{R} 1$ to $A_{w}$ results in an overall lower amount of removed tool material for cutting inserts with a larger initial rake angle.
In machining $\Phi=30^{\circ}$, the maximum values of $A_{w}$ after a total cutting length of $l_{c u t}=35 \mathrm{~m}$ clearly vary for the tested combinations of initial rake and clearance angles. With $A_{w}=9230 \mu \mathrm{m}^{2}$, the largest amount of removed tool material is found for tool geometry E (10/7), while with $A_{w}=3360 \mu \mathrm{m}^{2}$, the lowest amount of removed tool material is observed for tool geometry M (20/21). Accordingly, increasing the initial

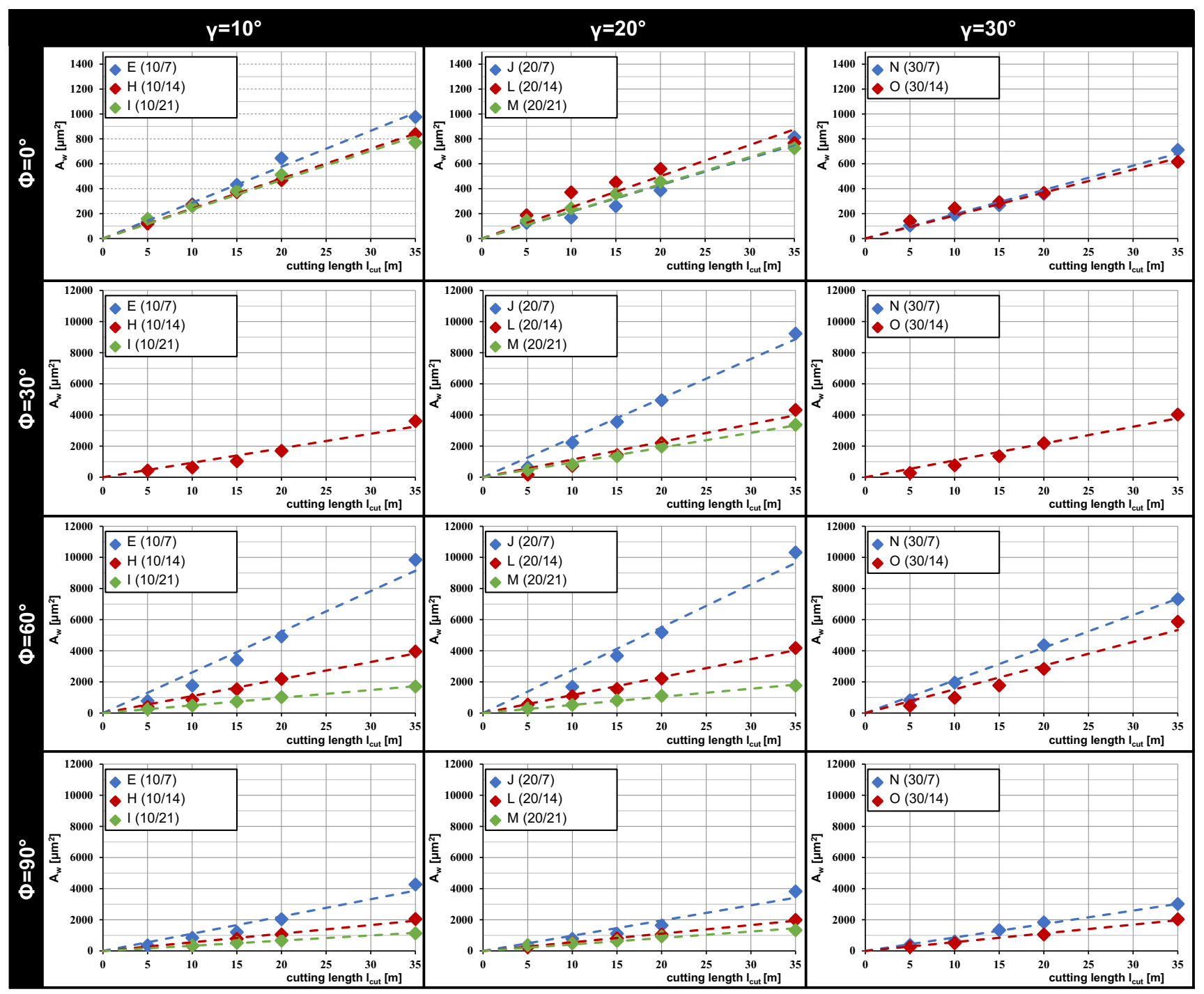

Fig. 16 Wear-related trend of $A_{w}$ as function of the tool geometry, the fibre cutting angle and the cutting length $\left(v_{c}=90 \mathrm{~m} / \mathrm{min}, f=0.03 \mathrm{~mm} / \mathrm{rev}\right)$ 
clearance angle from $\alpha=7^{\circ}$ to $\alpha=21^{\circ}$ results in an approximately three times higher material loss. Differences in tool wear are mainly found in R3, while the wear behaviour for $\mathrm{R} 1$ and R2 is comparable for all tested tool geometries. Consequently, the abovementioned differences in material loss are particularly caused by flank wear effects.

For $\Phi=60^{\circ}$, the wear-related trend of $A_{w}$ and the resulting magnitude are comparable to those found for $\Phi=30^{\circ}$. With $A_{w}=10320 \mu^{2}$, the largest amount of removed tool material is identified for tool geometry E (20/7), while with $A_{w}=1705$ $\mu \mathrm{m}^{2}$, the lowest amount of removed tool material is found for tool geometry I (10/21). Considerable differences in $A_{w}$ for the tested fibre cutting angles in interval II are only observed for tool geometry M (20/21), where $A_{w}$ after $l_{c u t}=35 \mathrm{~m}$ is clearly lower for $\Phi=60^{\circ}$ than for $\Phi=30^{\circ}$. According to Section 5.3, this is explained by occurring subsurface damages, which are particularly found in machining $\Phi=60^{\circ}$ with large initial clearance angles.

For $\Phi=90^{\circ}$, with $A_{w}=4270 \mu \mathrm{m}^{2}$ and $A_{w}=1130 \mu \mathrm{m}^{2}$, the largest and lowest amount of removed tool material are measured for tool geometries E (10/7) and I (10/21). Accordingly, the wear potential in machining $\Phi=90^{\circ}$ is higher than for $\Phi=0^{\circ}$ but lower than for $\Phi=30^{\circ}$ and $\Phi=60^{\circ}$.

As a general rule of thumb, which is independent on the fibre cutting angle, it can be stated that not only the bouncing back height and the friction length but also the loss of tool material due to wear is larger, the smaller the initial clearance and rake angles of the cutting insert are. However, the actual amount of removed tool material strongly varies for different fibre cutting angles, since the corresponding process forces, the spring back potential of the CFRP material and the tool/ workpiece contact area are different.

\section{Conclusion}

Severe mechanical wear at the cutting tool is one of the main issues in machining CFRP and primarily responsible for a limited tool life. Progressive tool wear is associated with a continuous changing active micro-geometry, which affects the tool/material interaction in the contact zone and thus the resulting process forces and the tool performance. This experimental study deals with a fundamental tool wear analysis in orthogonal machining of UD CFRP material with different combinations of fibre cutting angles and tool geometries. The presented experimental results and the documented interrelations between the tool geometry, the fibre cutting angle, and the wear behaviour represent valuable information for tool manufacturer that are interested in enhancing the cutting tool performance in order to reduce the wear-related change of the tool's micro-geometry. The listing below gives a summary of the key findings of this work:
- Tool wear in R1 (rake face) is only found for machining $\Phi=0^{\circ}$ for tool geometries with an initial rake angle smaller than $\gamma=30^{\circ}$. For these tool geometries, progressive tool wear is characterised by a non-uniform material loss on the rake face which reaches its maximum in point $B$ and decreases to zero in direction of point A. Therefore, the tools rake angle continuously decreases and is identical to zero after a cutting length of $l_{c u t}=10 \mathrm{~m}$ and $l_{\text {cut }}=35 \mathrm{~m}$ for initial rake angles of $\gamma=10^{\circ}$ and $\gamma=20^{\circ}$, respectively.

- Tool wear in R2 (cutting edge rounding) is found for all tested tool geometries and fibre cutting angles. In this context, the parameter $l_{\alpha}$ always increases clearly faster than $l_{\gamma}$ resulting in an asymmetric cutting edge rounding. It is shown that compared to $l_{\alpha}$, the value of $l_{\gamma}$ after a cutting length of $l_{c u l}=35 \mathrm{~m}$ is smaller, the larger the fibre cutting angle is. The influence of the initial set of rake and clearance angles on the wear progressions of $l_{\gamma}$ and $l_{\alpha}$ is small.

- With the exception of machining $\Phi=90^{\circ}$ with an initial clearance angle of $\alpha=21^{\circ}$, tool wear in R3 (flank face) is found for all tested tool geometries and fibre cutting angles. Progressive tool wear is characterised by a continuous decreasing clearance angle, while simultaneously the corresponding contact length increases due to an intensified spring back of the CFRP material. The tool's wear behaviour in $\mathrm{R} 3$ is dominated by the fibre orientation and the initial clearance angle, while the influence of the initial rake angle is negligible.

- Especially for machining $\Phi=60^{\circ}$ and $\Phi=90^{\circ}$ with initial clearance angles of $\alpha=14^{\circ}$ and $\alpha=21^{\circ}$, extensive subsurface damages in the machined surface are identified which cannot be removed by the subsequent spindle rotation. Occurring subsurface damages reduce the material's spring back potential resulting in a clearly lower bouncing back height.

- For all tested tool geometries and fibre orientations, the bouncing back height increases with increasing cutting length. In combination with a simultaneously decreasing clearance angle, a longer friction length on the flank face is identified. The bouncing back height is found to be highly dependent on the initial clearance angle and the fibre cutting angle. With respect to the tool geometry, the bouncing back height is higher, the smaller the initial clearance angle is. With respect to the fibre cutting angle, the bouncing back height first increases from $\Phi=0^{\circ}$ to $\Phi=30^{\circ}$ but decreases again if the fibre cutting angle is further increased to $\Phi=60^{\circ}$ and $\Phi=90^{\circ}$. This is explained by the subsurface damages that reduce the spring back potential of the CFRP material.

- The removed tool material per cutting length shows almost a linear trend which means that the wear rate is not affected by the changing cutting edge geometry. Instead, the same amount of removed tool material is distributed 
over a larger active micro-geometry. The most intense material loss is identified in machining $\Phi=30^{\circ}$ and $\Phi=60^{\circ}$ with a small initial clearance angle.

- The proposed technique for measuring the bouncing back height represents an efficient method for identifying the actual contact zone of the cutting edge and thus the active micro-geometry. However, it must be noted that it is only applicable for machining situations with a constant fibre cutting angle. For machining situations, where the value of $\Phi$ changes during the measurement, only the maximum bouncing back height is measureable as it defines the displacement of the laser marks. Currently, only one orthogonal machining experiment for each combination of tool geometry and fibre cutting angle is used for the wear analysis. Extended experimental effort has to be undertaken for a detailed statistical analysis of the wear parameters.

Acknowledgements The authors thank the companies Dixi Polytool SA, Heule Werkzeuge AG, Oerlikon Surface Solutions AG, and Airbus Helicopters Deutschland $\mathrm{GmbH}$ for their support.

Availability of data and material All necessary data is shown in the figures within the document. The raw data can be made available upon request.

\section{Code availability Not applicable}

Authors Contributions Lukas Seeholzer: Conceptualisation, data curation, formal analysis, investigation, methodology, project administration, resources, software, supervision, validation, visualisation, roles/ writing - original draft, and writing - review and editing

Fabian Kneubühler: Visualisation, roles/writing - original draft, and writing - review and editing

Frank Grossenbacher: Investigation

Konrad Wegener: Funding acquisition, supervision, and review and editing

Funding Open Access funding provided by ETH Zurich. This research was funded by the Swiss Innovation Agency (Innosuisse Project 18309.2 PFIW-IW).

\section{Declarations}

Competing interests The authors declare no competing interests.

Open Access This article is licensed under a Creative Commons Attribution 4.0 International License, which permits use, sharing, adaptation, distribution and reproduction in any medium or format, as long as you give appropriate credit to the original author(s) and the source, provide a link to the Creative Commons licence, and indicate if changes were made. The images or other third party material in this article are included in the article's Creative Commons licence, unless indicated otherwise in a credit line to the material. If material is not included in the article's Creative Commons licence and your intended use is not permitted by statutory regulation or exceeds the permitted use, you will need to obtain permission directly from the copyright holder. To view a copy of this licence, visit http://creativecommons.org/licenses/by/4.0/.

\section{References}

1. Schürmann H (2008) Konstruieren mit Faser-KunststoffVerbunden. Springer, Berlin

2. Geier N, Pereszlai C (2020) Analysis of characteristics of surface roughness of machined CFRP composites. Period Polytech Mech Eng 64(1):67-80

3. Wan M, Li S-E, Yuan H, Zhang W-H (2019) Cutting force modelling in machining of fiber-reinforced polymer matrix composites (PMCs): a review. Compos A: Appl Sci Manuf 117:34-55

4. Khanna N, Pusavec F, Agrawal C, Krolczyk GM (2020) Measurement and evaluation of hole attributes for drilling CFRP composites using an indigenously developed cryogenic machining facility. Measurement 154:107504

5. Sheikh-Ahmad JY (2009) Machining of polymer composites. Springer. https://citations.springernature.com/book?doi=10.1007/ 978-0-387-68619-6

6. Rummenhöller S (1996) Werkstofforientierte Prozeßauslegung für das Fräsen kohlenstoffaserverstärkter Kunststoffe. RWTH Shaker Verlag Aachen, Aachen

7. Wang D, Ramulu M, Arola D (1995) Orthogonal cutting mechanisms of graphite/epoxy composite. Part I: unidirectional laminate. Int J Mach Tools Manuf 35(12):1623-1638

8. Henerichs M, Voss R, Kuster F, Wegener K (2015) Machining of carbon fiber reinforced plastics: Influence of tool geometry and fiber orientation on the machining forces. CIRP J Manuf Sci Technol 9:136-145

9. Wang X, Zhang L (2003) An experimental investigation into the orthogonal cutting of unidirectional fibre reinforced plastics. Int $\mathrm{J}$ Mach Tools Manuf 43(10):1015-1022

10. Maegawa S, Morikawa Y, Hayakawa S, Itoigawa F, Nakamura T (2016) Mechanism for changes in cutting forces for down-milling of unidirectional carbon fiber reinforced polymer laminates: modeling and experimentation. Int J Mach Tools Manuf 100:7-13

11. Wang X, Kwon PY, Sturtevant C, Lantrip J (2013) Tool wear of coated drills in drilling CFRP. J Manuf Process 15(1):127-135

12. Nguyen D, Abdullah MSB, Khawarizmi R, Kim D, Kwon P (2020) The effect of fiber orientation on tool wear in edge-trimming of carbon fiber reinforced plastics (CFRP) laminates. Wear 450: 203213

13. Cirino M, Friedrich K, Pipes R (1988) The effect of fiber orientation on the abrasive wear behavior of polymer composite materials. Wear 121(2): 127-141

14. Madhavan V, Lipczynski G, Lane B, Whitenton E (2015) Fiber orientation angle effects in machining of unidirectional CFRP laminated composites. J Manuf Process 20:431-442

15. Dandekar CR, Shin YC (2012) Modeling of machining of composite materials: a review. Int J Mach Tools Manuf 57:102-121

16. Bitans K, Brown R (1965) An investigation of the deformation in orthogonal cutting. Int J Mach Tool Des Res 5(3):155-165

17. Wern C, Ramulu M, Shukla A (1994) Investigation of stresses in he orthogonal cutting of fiber-reinforced plastics. Exp Mech 36(1):3341

18. Iș1k B, Altan E (2011) Cutting forces in orthogonal turning of undirectional glass fibre reinforced plastic composites. Adv Compos Lett 20(1):5

19. Wang C, Liu G, An Q, Chen M (2017) Occurrence and formation mechanism of surface cavity defects during orthogonal milling of CFRP laminates. Compos Part B 109(Supplement C):10-22. https://doi.org/10.1016/j.compositesb.2016.10.015

20. Koplev A, Lystrup A, Vorm T (1983) The cutting process, chips, and cutting forces in machining CFRP. Composites 14(4):371-376

21. Davim JP (2009) Machining composite materials. John Wiley \& Sons, Hoboken. https://www.wiley.com/en-us/Machining+ Composites+Materials-p-9781848211704 
22. Voss R, Seeholzer L, Kuster F, Wegener K (2018) Analytical force model for orthogonal machining of unidirectional carbon fibre reinforced polymers (CFRP) as a function of the fibre orientation. $\mathrm{J}$ Mater Process Technol 263:440-469

23. Sharma M, Rao IM, Bijwe J (2010) Influence of fiber orientation on abrasive wear of unidirectionally reinforced carbon fiberpolyetherimide composites. Tribol Int 43(5):959-964

24. Caprino G, Nele L, Santo L (1996) Effect of tool wear on cutting forces in the orthogonal cutting of unidirectional glass fibrereinforced plastics. Compos A: Appl Sci Manuf 27(5):409-415

25. Tagliaferri V, Caprino G, Diterlizzi A (1990) Effect of drilling parameters on the finish and mechanical properties of GFRP composites. Int J Mach Tools Manuf 30(1):77-84

26. Ferreira J, Coppini N, Miranda G (1999) Machining optimisation in carbon fibre reinforced composite materials. J Mater Process Technol 92:135-140

27. Sakuma K, Seto M, Tanigchi M, Yokoo Y (1985) Tool wear in cutting carbon-fiber-reinforced plastics: the effect of physical properties of tool materials. Bull JSME 28(245):2781-2788

28. Voss R (2017) Fundamentals of Carbon Fibre Reinforced Polymer (CFRP) Machining. Eidgenossische Technische Hochschule Zurich (ETH). https://www.research-collection.ethz.ch/handle/20. $500.11850 / 165454$

29. Maegawa S, Hayakawa S, Itoigawa F, Nakamura T (2016) Twolayer tool with hardness distribution around tool edge for reducing cutting forces in CFRP machining. Int J Autom Technol 10(3):364371

30. Voss R, Henerichs M, Kuster F, Wegener K (2014) Chip root analysis after machining carbon fiber reinforced plastics (CFRP) at different fiber orientations. Paper presented at the CIRP HPC, Berkeley

31. Xu W, Zhang L (2018) Tool wear and its effect on the surface integrity in the machining of fibre-reinforced polymer composites. Compos Struct 188:257-265

32. Ramirez C, Poulachon G, Rossi F, M'Saoubi R (2014) Tool wear monitoring and hole surface quality during CFRP drilling. Procedia CIRP 13:163-168

33. Ramulu M (1997) Machining and surface integrity of fibrereinforced plastic composites. Sadhana 22(3):449-472

34. Faraz A, Biermann D, Weinert K (2009) Cutting edge rounding: an innovative tool wear criterion in drilling CFRP composite laminates. Int J Mach Tools Manuf 49(15):1185-1196. https://doi.org/ 10.1016/j.ijmachtools.2009.08.002

35. Voss R, Henerichs M, Rupp S, Kuster F, Wegener K (2016) Evaluation of bore exit quality for fibre reinforced plastics including delamination and uncut fibres. CIRP J Manuf Sci Technol 12: 56-66. https://doi.org/10.1016/j.cirpj.2015.09.003

36. Chennakesavelu G (2010) Orthogonal machining of uni-directional carbon fiber reinforced polymer composites. Wichita State University
37. Hou G, Qiu J, Zhang K, Cao S, Cheng H, Luo B, Cheng Y (2019) Comparative tool wear and hole quality investigation in drilling of aerospace grade T800 CFRP using different external cooling lubricants. Int J Adv Manuf Technol 1-15. https://link.springer.com/ article/10.1007/s00170-019-04554-9

38. Fu R, Jia Z, Wang F, Jin Y, Sun D, Yang L, Cheng D (2018) Drillexit temperature characteristics in drilling of UD and MD CFRP composites based on infrared thermography. Int J Mach Tools Manuf 135:24-37

39. Khairusshima MN, Hassan CC, Jaharah A, Amin A, Idriss AM (2013) Effect of chilled air on tool wear and workpiece quality during milling of carbon fibre-reinforced plastic. Wear 302(1-2): 1113-1123

40. Abish J, Samal P, Narenther M, Kannan C, Balan A (2018) Assessment of drilling-induced damage in CFRP under chilled air environment. Mater Manuf Process 33(12):1361-1368

41. Henerichs M (2015) Bohrbearbeitung von CFK unter besonderer Berücksichtigung der Schneidkantenmikrogeometrie. Eidgenössische Technische Hochschule Zürich (ETH), Zürich

42. Zhang LC, Zhang HJ, Wang XM (2001) A force prediction model for cutting unidirectional fibre-reinforced plastics. Mach Sci Technol 5(3):293-305. https://doi.org/10.1081/MST-100108616

43. Raj DS, Karunamoorthy L (2018) A new and comprehensive characterisation of tool wear in CFRP drilling using micro-geometry and topography studies on the cutting edge. J Manuf Process 32: 839-856

44. Hexcel-Corporation (2015) HexPly M21 Product Data Sheet. Hexcel. https://www.hexcel.com/user_area/content_media/raw/ HexPly_M21_global_DataSheet.pdf. Accessed 07.10.2019 2019

45. Seeholzer L, Voss R, Grossenbacher F, Kuster F, Wegener K (2018) Fundamental analysis of the cutting edge micro-geometry in orthogonal machining of unidirectional carbon fibre reinforced plastics (CFRP). Procedia CIRP 77:379-382

46. Xu YL, Reifsnider KL (1993) Micromechanical modeling of composite compressive strength. J Compos Mater 27(6):572-588

47. Usui E, Shirakashi T, Kitagawa T (1984) Analytical prediction of cutting tool wear. Wear 100(1-3):129-151

48. Qi Z, Zhang K, Cheng H, Wang D, Meng Q (2015) Microscopic mechanism based force prediction in orthogonal cutting of unidirectional CFRP. Int J Adv Manuf Technol 79(5):1209-1219. https://doi.org/10.1007/s00170-015-6895-7

49. Hetényi M (1946) Beams on elastic foundation: theory with applications in the fields of civil and mechanical engineering. University of Michigan press, Ann Arbor

Publisher's note Springer Nature remains neutral with regard to jurisdictional claims in published maps and institutional affiliations. 